\title{
Labor Market Indicator for Colombia
}

Deicy J. Cristiano-Botia ${ }^{\dagger}$, Manuel Dario Hernandez-Bejarano and Mario A. Ramos-Veloza ${ }^{1} \S$ e-mail: dcristbo@banrep.gov.co, Banco de la República, Bogotá, Colombia.

* e-mail: mdh5718@psu.edu, Pennsylvania State University, EEUU.

\& Correspondence: mramosve@banrep.gov.co, Banco de la República, Bogotá, Colombia. The opinions contained in this document are the sole responsibility of the authors, and do not commi Banco de la República or its Board of Directors.

\begin{abstract}
Although the unemployment rate is traditionally used to diagnose the current state of the labor market, this indicator does not reflect the existence of asymmetries, mobility costs, and rigidities which impede labor to freely flow over the business cycle. Thus, to get a better portrait of the momentum, we construct the Labor Market Indicator (LMI) focusing on the cyclical similarities of eighteen time series from the Colombian household, industrial, and opinion surveys between 2001 and 2019. Our indicator summarizes the growth cycle of the labor market and its evolution is closely related to the output and unemployment GAP. This indicator is useful for policy analysis as it is useful to forecast headline inflation, it also complements the diagnosis of the current momentum of the labor market, the general economic activity, and the characterization of economic phases and turning points.
\end{abstract}

Keywords: LMI, Colombian labor market, dynamic factor model, unemployment rate.

JEL classification: E24, E66, J6, J20 


\section{Introduction}

Economic growth is not a stable and smooth process, given that internal and external disturbances, institutions, and economic policy may affect the short-run growth rate causing instabilities, i.e., business cycles. As sources of the cycles might be different, their duration, intensity, and diffusion also vary from one cycle to the next. Research on business cycles has defined two phases for the economic activity: periods with positive economic growth in which conditions are favorable in almost all economic sectors (expansions), and periods with negative economic growth in which the economic indicators deteriorate for most of the economic activities (recessions). The labor market is also affected by business cycles as workers and firms adjust their supply and demand decisions to the prevailing conditions. ${ }^{1}$ The response of the labor market will sum the benefits and losses from all economic sectors and agents and may change depending on macroeconomic conditions like the origin of the cycle, how expansions and recessions spread among economic activities, as well as industry conditions such as labor intensity or final product orientation. For instance, as the investment is more sensitive to shocks than consumer goods, we expect that recessions start with a deterioration of employment, vacancies, and expectations in the production of investment goods.

Traditionally, the analysis of the business cycle's effects over the labor market has been conducted using the unemployment rate (UR) given the classical view that cyclical fluctuations are the main force behind the movements in unemployment. However, the existence of rigidities such as mobility costs and information asymmetries also play an important role in explaining unemployment (e.g., Lilien (1982), Loungani (1986), and Davis (1987)). These rigidities impede labor to flow among sectors during recessions freely. Thus, it is convenient to expand our attention to variables that reflect other aspects of the labor market not affected by these rigidities. Among these variables, we find vacancies, job creation, and productivity; thus, creating a composite indicator that provides a better portrait of how the labor market absorbs economic fluctuations over the business cycle.

Moreover, research on the business cycle has analyzed the behavior of economic series during upturns and downturns, finding that: i) fluctuations have common patterns on economic activity, ii) fluctuations vary across countries despite their similar characteristics, and iii) contractions tend to be shorter and deeper than expansions (e.g., Mitchell (1927) and Keynes (1936)). Specialized institutions have used the first conclusion to construct indicators that describe the deepness, length, and diffusion of thebusiness cycle, providing a diagnostic of current conditions to formulate economic policy. In practice, three alternative indicators have been introduced, each definition focusing on different properties of the series. The Conference Board and the Euro committee construct business cycle indicators using logarithms or levels of a wide set of economic series. Mintz (1972) proposes two additional cycles the growth cycle, which focus on each series deviation with respect to its long-run trend, and the acceleration cycle, which analyze changes in the growth rate of the variables. Phases and turning points from each definition describe different features from the business cycle, and therefore combining them will help to identify recessions and to make better policy design. Although, usually statistical agencies construct traditional business cycle indicators currently there is an increasing interest in the growth cycle definition, as the Organisation for Economic Cooperation and Development (OECD) used this definition to compute their cyclical indicator system.

The agencies that construct these indices have found that summarizing signals from various indicators to diagnose the labor market is not straightforward. For instance, between 2005 and 2008, economic growth in Colombia exceeded 5\%, an improvement that leads to a reduction of the unemployment and the underemployment rates of $0.76 \mathrm{pp}$ and $2.00 \mathrm{pp}$, reflecting a better

1 During recessions, the labor supply of secondary members of the household may increase to compensate income reductions consequence of fires or hours cut of other household members. Additionally, labor demand is adjusted as firms optimize their overtime hours, vacancies, and full-time employment to face the changing economic environment. 
momentum of the labor market. However, a measure of the whole improvement is not directly derived. The problem of diagnosing the labor market's current state is harder with multiple sources of information, horizons, or units of measurement. Then, to understand the current state of the labor market is necessary to develop an indicator that summarizes the behavior of a broad set of series.

A first way to deal with this problem is the use of traditional statistical techniques. For instance, the Conference Board constructs composite indices as the average growth of the series, correcting by its volatility and rescaling them to equate their trends to the trend of the coincident index. Also, diffusion indices are computed as the proportion of time series improving with respect to the previous year. Thus, both indices portray the state of the economy depending on how much economic conditions have spread over the set of series. However, those indices have two weaknesses: first, the weights are imposed ad-hoc, and second, the aggregation of the indicator does not remove idiosyncratic movements. An alternative solution is to portrait the state of the economy as a latent factor that drives the evolution of the series, which has been accomplished by the introduction of Principal Component Analysis (PCA) and Dynamic Factor Models (DFM). This approach overcomes the difficulties described given that the weights depend on the co-movement of each series with the underlying factor and the idiosyncratic movements are easily included in the specification. These techniques have beenused in economics to construct coincident, lagged, and leading indexes of the state of the economic activity, see for instance

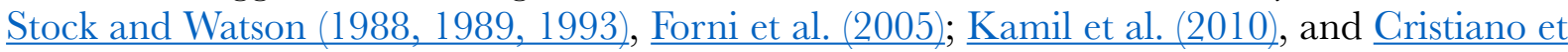
al. (2012) and Nieto and Melo (2001) for Colombia.

Four studies have constructed synthetic indicators to summarize the cyclical behavior of the labor market. Barnes et al. (2007) constructed the labor market indicator using the first principal component of twelve series that describe the labor market dynamics. The authors suggest that this indicatoris a good summary and capture the common movements as it accounts for $68 \%$ of the variation of the underlying series. Results show that for the UR and their indicator there are similarities in their cyclical components and in their predictive power to forecast wage inflation. Zmitrowicz and Khan (2014) also highlight that a better overview of the labor market is obtained using a broad range of information and compute the labor market indicator for both the United States and Canada as the first principal component of a set of labor market series. The indicator is re-scaled to coincide with the UR, and is interpreted as the UR consistent with the actual labor market conditions. A lower increment of the indicator than the observed in the UR will signal a better diagnostic and is consistent with a positive dynamics in other indicators. Their results show a similar evolution for both indicators; however, the evolution of the UR has modestly overestimated the improvement since the recession.

Hakkio and Willis (2013) consolidated 23 labor market series using PCA; they select the two principal components that account for $82 \%$ of the series co-movements. The first factor is related to the level of activity describing current labor market conditions and this assessment can be compared over time, this factor is computed including various measures of unemployment, such as the traditional rate, one including marginally attached workers, and the long-term unemployed. On the other hand, the second factor describes the speed of improvement of current conditions, including among other variables the growth rates of private employment, total hours worked, and average hourly earnings. The authors suggest to use both factors in the characterization of the current and future conditions and how fast they would reach some value of reference. $^{2}$

The most recent paper is Chung et al. (2014) who combine a DFM and PCA to construct the labor market conditions index in two steps. In the first step, the three most representative dynamic latent factors are extracted from a wide set of labor market series. In the second step, the indicator is constructed as the first principal component of the common variation of the

2 On table 6 in the appendix there is a description of all variables included in the previous studies grouped by labor market categories. 
series. $^{3}$ Sixty-six percent of the total co-movement is captured by the final indicator, which is useful to forecast each series one-step ahead. As far as we are concerned, there is no evidence of indicators to assess the momentum of the labor market in developing economies, which have different economic and social institutions than industrialized countries. Thus, in addition to standard labor market indicators in developing economies, attention must be placed on nonwage occupation and inactivity.

The objective of this paper is to construct an aggregate growth cycle indicator for the Colombian labor market that provides policy makers with additional information than both the traditional business cycle indicators and the unemployment rate to evaluate the current state of the labor market and the general economic activity. Thus, our indicator can be used in three possible ways: first, it is a measure of the slackness in the labor market and the overall economy, it extends the diagnostic of the labor market momentum and shows whether movements in the general economy affect the labor market; for this latter reason Jacob and Robinson (2019) suggest to use a suite of various indicators to determine current economic conditions, given that the output GAP is quarterly and prone to big revisions. Second, as the LMI is a measure of slackness it could be used to forecast inflation in a Phillips curve directly or in a forecast combination. Finally, it may provide information about changes in economic conditions given that it is monthly and that the end of the high-growth phase (downturn point) leads the peak of the expansions. We follow a dynamic factor model approach to summarize information from a wide set of labor market series (households, commerce, and industrial surveys, as well as administrative records). This approach considers optimal weights to maximize the common variation, captures the dynamic behavior of both the common factors and the idiosyncratic components, and allows to handle missing observations efficiently: $i$ ) due to different spans of information, as more series are recently available, and ii) due to delays in publication or randomly missed.

Our results suggest that the LMI is mainly driven by industrial and commercial employment, bottlenecks, and vacancies, then, it complements the analysis of the labor market momentum as it is not mainly driven by the unemployment rate. Additionally, its evolution is similar to the one of general economic activity in the majority of the period, but the differences provide information about what movements in economic activity are not reflected on the labor market. Its interpretation also complements the diagnostic from the expansions of the traditional business cycle indicators, given that this indicator also shows whether the growth cycle is improving. Finally, our results also show that the indicator is useful to forecast in and out of sample headline inflation using a traditional Phillips Curve augmented with expectations.

This document is divided into seven sections being the first this introduction. The second section describes the methodology used to construct the index; in the first step, we extract the maximum common variation with a DFM, and in the second step, we compute the LMI as the first principal component of the projected series. In the third section, we discuss the set of variables and how the cyclical component was extracted. The fourth section presents a deeper interpretation of the growth cycle indices and their relationship with the traditional business cycle. In the fifth section, we present the LMI between 2001 and 2019 its phases and present a robust analysis changing the sample to see whether new information changes the turning points. In the sixth section, we compare the ability of the LMI to diagnose the current momentum of the labor market and the economy comparing it with the GDP and UR gaps for Colombia, we also investigate the in-sample and out-sample performance in forecasting headline inflation. Finally, we combine the evolution of our indicator and a traditional diffusion index to capture and describe the state of the business cycle, we conclude in the last section.

3 The common variation of the entire set of series is constructed as the prediction of the entire set of series using only the latent factors computed in the first step. 


\section{Methodology}

This section presents the methodology to extract the common movement across the cyclical behavior of the series in an indicator that tracks the current state of the labor market. In the first step, we decompose a vector of $n_{v}$ cyclical components of a set of labor market series $X_{t}$ into two components: a group of $n_{f}$ latent factors $F_{t}$ that is common across all series and a set of idiosyncratic series $U_{t}$ that capture the idiosyncratic evolution of each series.

$$
X_{t}=\Lambda F_{t}+U_{t}
$$

where $\Lambda$ is a $\left(n_{v}, n_{f}\right)$ matrix that corresponds to the loading coefficients of the factors in each observed variable, that is, how much each factor contributes to each series dynamics at pe$\operatorname{riod} t . U_{t}$ captures each series non-observed idiosyncratic component; this component describes the dynamics due to shocks and the proper movements of each series. In our application, it follows an autoregressive structure of lag $p_{u}{ }^{4}$

$$
U_{t}=C_{0}+C_{1} U_{t-1}+\cdots+C_{p_{u}} U_{t-p_{u}}+\eta_{u, t}
$$

with $C_{i}\left(n_{v}, n_{v}\right)$ diagonal matrices for $i=\left\{1,2, \ldots, p_{u}\right\}$, and $C_{0}$ is a $n_{v}$ vector that contains the intercepts of the AR processes. $\eta_{u, t}$ is a $n_{v}$ vector assumed Gaussian and uncorrelated across time nor with the other observed variables. Thus, the dynamic of the series due to the common component is given by $\Lambda F_{t}$ and that due to the idiosyncratic component is $U_{t}$, which does not provide information about the current state of the labor market or any other idiosyncratic component, this is a common assumption used for instance by Stock and Watson (1989). ${ }^{5}$ As the factors describe underlying economic forces, they follow a $\operatorname{VAR}\left(p_{f}\right)$ :

$$
F_{t}=A_{1} F_{t-1}+\cdots+A_{p f} F_{t-p f}+\eta_{f, t}
$$

with $A_{1}, \ldots, A_{p}\left(n_{f}, n_{f}\right)$ matrices that capture the dynamic relationship of the factors. $\eta_{f, t}$ is a $\eta_{f}$ vector of i.i.d Gaussian errors, with $\eta_{u, t}$ and $\eta_{f, t}$ i.i.d. disturbances. Equations (1) to (3) represent the DFM that can be converted into a linear state space representation using two equations. The first is the measurement equation that relates the observed variables to the latent factors, and the second is the transition equation that describes the evolution of the factors and the idiosyncratic component. The linear state space model is estimated using the Kalman Filter to evaluate the likelihood function (Harvey, 1990), the appropriate state-space representation can be found in appendix B.

The second step of the methodology is to compute the LMI, then once the latent factors have been estimated, we eliminate the variation of the series due to the idiosyncratic components by projecting each series using only the factors $\left(\widehat{X}_{t}=\widehat{\Lambda} \widehat{F}_{t}\right)$. Subsequently, the LMI is constructed as the first principal component of the projected series $\left(\widehat{X}_{t}\right)$.

$$
L M I_{t}=\Theta X_{t}=\Theta \widehat{\Lambda} \widehat{F}_{t}
$$

with $\Theta$ as the eigenvector of the matrix $\widehat{\Lambda} \operatorname{var}\left(\widehat{F}_{t}\right) \widehat{\Lambda}^{\prime}$ that corresponds to the highest eigenvalue.

4 The inclusion of an autoregressive factor for each idiosyncratic component follows Stock and Watson (2011) and is the principal difference between the proposed methodology and Chung et al. (2014). We expect to isolate idiosyncratic variation that may contaminate the factors and LMI dynamics.

5 It is also possible to model an idiosyncratic component that affects a small group of series. 


\section{Data and statistical treatment}

\section{Description of the database}

The main source of information regarding the labor market in Colombia is the household monthly survey published by DANE, but in recent years other aspects of the labor market are gathered in opinion surveys, administrative records, and industrial and commerce surveys. For instance, business expectations and vacancies are computed and published by Banco de la República (BR), and with more recent information of household surveys flow measures can be constructed, Morales et al.(2018) ${ }^{6}$. Although it would be desirable to include the majority of indicators, extracting a signal in large specifications is more difficult and may lead to worse performance (e.g., Boivin and Ng (2006), Ruiz and Poncela (2012), and Banbura and Modugno (2012)). Thus, to select the series we characterize all dimensions of the labor market keeping a reasonable number of series. We start by including seven key indicators of the labor market that Arango et al. (2015) discuss in their analysis of the labor market and the Colombian business cycle between 1984 and 2014. Additionally, to account for more dimensions of the labor market and to take advantage of the new information available since 2002, we include eleven variables from industrial, commerce, and expectations surveys. The selected series satisfy the traditional requirements for series used in business cycle indicators, as they are quickly available, their methodology is reliable, they are affected by the cycle, and finally, they are no subject to erratic behavior. ${ }^{7}$ Then, our series represent different dimensions such as unemployment, hours, wages, vacancies, hiring, firing, quits, and opinion surveys, the variables are presented in Table $1 .{ }^{8}$

\section{Unemployment and Underemployment}

The unemployment rate has been considered the most important indicator in the analysis of the labor market performance, its behavior is countercyclical as better conditions imply a higher level of employment and fewer people will look for a job. This variable was extracted from the Official Household Survey (GEIH by its acronym in Spanish). Another traditional indicator is the labor force participation rate (LFPR). This is computed as the percentage of the working-age population, which is either working or looking for a job, and reflects the decision to offer their labor services at an extensive margin. However, its relationship with the business cycle is not clear due to two opposite effects: the added and the discouraged worker. The first one is countercyclical given that secondary members of the household increase their participation during recessions to compensate the income reductions in the household due to layoffs or longer spells into unemployment. The second one is procyclical given that during recessions the expected wage reduces as the probability of finding a job and the actual wage reduces. The objective underemployment rate by hours (UER) is included as a measure of underutilization, it captures the proportion of not fully employed workers that may generate pressure on the labor market. It is defined as the percentage of employees that $i$ ) are currently working less than 32 hours per week, ii) want to work more hours, and iii) are available to work. Finally, we include a measure of discouraged workers (DC), that is, people that stop looking for job and go to the inactivity.

6 An alternative method to construct labor markets flows form the firm's perspective is based on the Planilla Integrada de Liquidación de Aportes (PILA) which is an administrative record of the Ministry of Health and Social Protection, Morales and Medina (2016).

7 The selection of the series in the OECD indicators is made based on the following criteria: the co-movements with the economic activity, the time consistency of this relationship, the reliability of the statistical methodology, the availability of the information, the relevance of the business cycle as a factor that explains the series, and the no-erraticism nor high-volatility of the series.

8 We also check the statistical properties of our series, and we found evidence of unit root for everyone. The complete results of the Dickey Fuller tests are presented in Table 7 of appendix C. 


\section{Employment}

We include three measures of labor demand as it traditionally moves along with economic conditions and is watched for gauging the health of the economy. First, we consider the industrial employment with total industry employment (TIE) from the Monthly Manufacturing Survey (EMM, by its acronym in Spanish), as industry represents about 10\% of both the GDP and employment of the economy. This index captures the evolution of employment in firms with more than 10 employees in the manufacturing sector. The second measure corresponds to employees in particular firms $(\mathrm{PE})$, which corresponds to the interviewees that report to work for a non-state firm during the reference period and is computed using the GEIH. Finally, we include the total employment in commerce (TCE) as DANE reports and its monthly commerce survey.

\section{Non-wage employment}

In a developing country, after a negative shock the response of the economic agents might be differentfrom just going to the unemployment, for instance, agents may adjust the extensive margin, labor underutilization, or engage in informal activities. Thus, as Mondragón-Vélez et al. (2010) found, informality is countercyclical. However, informality is only included in a monthly basis since 2007, thus we use as a proxy the percentage of employed that are non-wage workers $\mathcal{N W P}$.

Table 1. Variables included in the LMI

\begin{tabular}{lll}
\hline \multicolumn{1}{c}{ Variable } & Acronym & Source \\
\hline \multicolumn{1}{c}{ Unemployment and Underemployment } & & \\
Unemployment rate & UR & GEIH \\
Labor force participation rate & LFPR & GEIH \\
Objective underemployment by hours & UER & GEIH \\
Discouraged workers rate & DC & GEIH
\end{tabular}

\section{Employment}

Occupation rate

ER

GEIH

Total employment - Industry

TIE EMM

Private employment

PE GEIH

Total employment index - Commerce

TCE

EMCM

Informal employment

Proportion of non-wage workers

NWP

GEIH

\section{Workweeks}


Table 1 (continued). Variables included in the LMI

\begin{tabular}{lll}
\hline \multicolumn{1}{c}{ Variable } & Acronym & Source \\
\hline \multicolumn{1}{c}{ Vacancies, perceptions, and expectations } & & \\
Job vacancies & $\mathrm{JV}$ & $\mathrm{BR}$ \\
Business expectations & $\mathrm{BP} 4$ & $\mathrm{BR}$ \\
Bottle Necks & $\mathrm{BN}$ & $\mathrm{BR}$ \\
& & \\
Fob creation & $\mathrm{JC}$ & $\mathrm{BR}$ \\
Churning & $\mathrm{CH}$ & $\mathrm{BR}$ \\
\hline
\end{tabular}

This table presents the labor market series included in the LMI; the first column describes the series while the second column presents the acronym used in this document. The source is presented in the last column.

Source: author's elaboration.

Workweeks

Labor utilization at the intensive margin is measured by the number of hours worked per week. Research considers that it is procyclical because during economic upturns working hours increase, and during economic downturns they decrease (e.g., Kydland and Prescott (1991); Cho and Cooley (1994)); also, employers tend to adjust working hours before modifying their workforce. Thus, we included average weekly hours $(H P W)$ for wage-earners, taken from GEIH since 2001.

Wages

Salaries and earnings for employees are key to understand their decision to enter the labor market. The evidence suggests a strong and positive correlation between the economic cycle, the employment rate, and the wage rate. During a favorable economic environment, firms raise their offered wages to attract workers, in a search framework, we think that a tight labor market attracts workers by an intertemporal substitution effect, increasing their current labor supply. In contrast, during economic downturns, the wage rate offered declines, and the add and discouraged worker effects take place. The final change in the wage rate will depend on the employment composition and the existence of rigidities. In this paper, we included two measures of labor income. For the employees in private or government firms, the average wage (AW) represents their hourly wage and given that in Colombia the non-wage workers represent half of the working population, we include for all non-wage earners employees the average labor income (ALI).

Vacancies, perceptions, and expectations

fob vacancies (JV) reflect the openings and perspectives of firms. In an economy where the expectations of entrepreneurs are positive, one would expect an increase in this indicator, but if expectations are negative, then openings at firms will be closed and vacancies will reduce. In this paper, we used the monthly information of classified advertisements provided by job sites to obtain the number of job vacancies over time, as described in Arango (2013).

Employment expectations (BP4) captures the expected labor demand 12 months ahead compared with the actual level, given the information available today (Firms are provided with a short report that includes information about current inflation, unemployment, GDP growth, and the nominal exchange rate). Thus, the answer to this question might depend on general economic conditions, as well to conditions in its own sector and firm idiosyncratic decisions. As we focus on the balance of this question, we capture the average change of employment. Moreover, this expectation connects the current employment with firm hiring and firing plans, given that changing the level of employment is costly and may take time, economic theory suggest that 
firms will smooth decisions over time. Thus, if expectations of production are good but there are incentives to reduce labor demand today, firms would avoid the costs of layoffs and rehiring and will maintain their current employment to keepup with future production plans. This connection among present and future conditions can be also presented in theoretical derivations of the GDP GAP where in the Phillips curve there are inflation expectations. Thus, given the existence of adjustment costs investment, hiring, firing, among other variables affect today's behavior and therefore are already included in today's potential GDP and its GAP. We used information provided by the Monthly Survey of Economic Expectations (EEE by its acronym in Spanish) and the balance is computed as the difference between the percentage of firms that will hire more employeesand the percentage of those that will reduce their plant in the next twelve months. The final variable that we include in our analysis, also comes from this survey and it portraits the current difficulties faced by firms to hire is the existence of bottlenecks $B N$.

\section{Fluidity Measures}

Labor flows provide more information about the functioning of the labor market than the simple changes in the stocks. Fob creation (JC) is computed as the number of employees created from one period to the next. In order to capture the labor overflow in the economy, we also included the measure of churning $(\mathrm{CH})$, which reflects the ratio between workers and job reallocations. We use the series proposed by Morales et al. (2018), who provide a measure of labor flows for wage and non-wage workers. This is a more comprehensive approach to understand flows than just focusing on wage workers from firm-level data Morales and Medina (2016) and Flórez et al. (2017).

Treatment of the series

In this subsection, we discuss the steps to extract a cyclical component of the series and estimate the DFM described in equations $1-3 .^{9}$ In order to avoid miss-specifications, false signals it is usual to remove the seasonal and permanent components in the construction of business cycle indicators. Thus, we test for seasonal autocorrelation in the original series using the QS test proposed by Gómez and Maravall (1996). Only three series did not require seasonal adjustment: average weekly hours (HPW), average wage (AW), and average labor income (ALI). Thus, we seasonally adjust the remaining fifteen series using the TRAMO-SEATS software. Maximo et al. (2015) strongly advise to use seasonally adjusted variables in a DFM since its performance is comparable or even better than the performance of a DFM that includes a common seasonal component. Their results suggest that including seasonal structure in a DFM will have the curse of dimensionality and additionally, the model might be miss-specified if the seasonal component is idiosyncratic, in our application, three series do not require adjustment.

We remove the permanent component of the data, detrend. Several filtering methodologies have been developed to decompose a time series into their permanent and cyclical components, being the most popular used Hodrick and Prescott (HP), Baxter and King (BK), and LOWESS (Locally Weighted Scatter Plot Smoothing). We choose the BK filter focusing on the cyclical component for frequencies between 6 months and 6 years; this eliminates high-frequency as well as undesired long-term components. Literature has shown that this filter has better performance at the business cycle frequencies. For instance, Kaiser and Maravall (1999) show that the Hodrick-Prescott filter produces spurious effects and it has a poorer approximation at the endpoints. ${ }^{10}$ As filters are characterized by end-point problems leading to false signals; we forecast the four-year non-observed period before the beginning and after the end of the sample. For the seven series included in Arango et al. (2015), we conduct conditional ARIMA models,

9 By construction cyclical components are stationary, then in our DFM model it is not necessary to consider any long run trend.

10 The OECD indicators are constructed considering Phase Average Trend (PAT), Hodrick and Prescott filter, and Christiano and Fitzgerald filter. 
assuming that the monthly series should reflect the same end of quarter change as the quarterly series. For the remaining variables, the forecasts are derived from an ARIMA $(p, d, q)$ model that minimizes the mean square forecast error of a rolling out of sample forecasting evaluation up to one year ahead, with a forecast sample that starts in January 2013.

\section{Traditional vs Growth cycle indicators}

Worldwide the analysis of the current state of the economy is crucial, while in the United States the Business Cycle Dating Committee and the Conference Board are the responsible institutions of this task, the Euro Area Business Cycle Dating Committee is the responsible for the eurozone. These institutions track the state of the main economic variables and construct indicators that summarize that behavior and determine whether current conditions signal a change in the economic phase. As mentioned in the introduction, there are three alternative measurements to construct the indicators: business cycle, growth cycle and acceleration cycles. Thus, in this section, we discuss the business cycle and growth cycle indicators and how to connect them for a clear interpretation of the LMI. Later, we introduce duration, deepness, and diffusion as concepts that must be combined with the turning points to correctly diagnose the current phase of the business cycle.

Traditionally, business cycle analysis focuses on determining whether the economy is in an expansion or recession phase, being those two phases separated by peaks and troughs, denominated turning points. An expansion describes a period of economic growth and begins after economic activity falls to its minimum (trough) and lasts up to it reaches the maximum (peak). On the other hand, a recession denotes a period of contraction in the economic activity and begins right after the economy reaches the peak of the previous expansion and ends when the economic activity falls to its trough. In the literature, indicators are constructed extracting the current state of the economy from the fluctuations on the level of a variety of economic activity series. As we focus on the cyclical component of the series, the LMI belongs to the growth cycles indicators, that is a strand of the business cycle literature initiated by Mintz (1972). Series are analyzed around its long-run trend instead of its level and the indicators are constructed similarly to in the traditional analysis. Similarly, these cycles also have two phases: high-growth and low-growth and the turning points separating those phases are called downturns and upturns. Growth cycles tend to be more frequent and symmetric than the traditional business cycle, where expansions are distinctively longer than recessions. Thus, acceleration and deceleration in growth might occur without a decline in the level of economic activity. A definition of growth cycles is provided by Mintz (1972) page 40:

\section{"... Growth cycles are fluctuations in aggregate economy activity. A growth cycle consists of a period of relatively high growth rates occurring at about the same time in many economic activities, followed by a period of similarly widespread low growth rates which merges into the high-growth phase of the next cycle..."}

Although there is no one-to-one connection between the traditional and the growth business cycle definitions, phases, and turning points, some links between the two methodologies can be established. First, in periods of a high-growth phase (growth definition), the growth exceeds the long-run trend, then those favorable conditions are related to an expansion (traditional definition). However, such connection cannot be established with low-growth periods, given that they may refer to periods of expansion with moderate economic growth or to recessions. For these reasons, high-rate phases tend to be shorter than expansions. During recessions (traditional definition), the growth is negative and therefore below the long-run trend; thus, the economy must also be in a low growth phase (growth definition). However, no association can be done with expansion periods, given that positive growth can be associated with both high and low growth phases. 
Concerning the turning points, Mintz (1972) highlights that while downturns tend to lead to peaks, upturns tend to lag troughs.

A comparison of the phases and the turning points from these definitions is presented in Figure 1. The upper panel presents a series that can be decomposed into a linear trend (black line) and a cyclical component (red line) presented in the lower panel. The chronology of the turning points is the following: first, we observe a downturn in economic activity, as marked by point $\mathrm{A}$, this implies that the economy falls into a low-growth phase, it will not become a recession until economic activity reaches its peak at point $\mathrm{B}$. At this point, there is a reduction in the level of the series, as the long-run trend growth does not compensate the reduction in the cyclical component. The recession will continue as the series continue reducing and reach its through in point C. Finally, the cyclical component of the series also reacts, and there is an upturn at point $\mathrm{D}$. Thus, in the example, the light grey shaded region represents a recession, and the whole shaded region (dark and light grey) will capture the low-growth phase. In this example, we can see that both the level and the cyclical component of the series have turning points. However, this could not be the case, if the reduction of the cyclical component is not big enough to offset the increments in the long-run trend, we will have turning points in the growth cycle indicators but not in the level indicators.

Figure 1. Comparison of the business cycle indicators

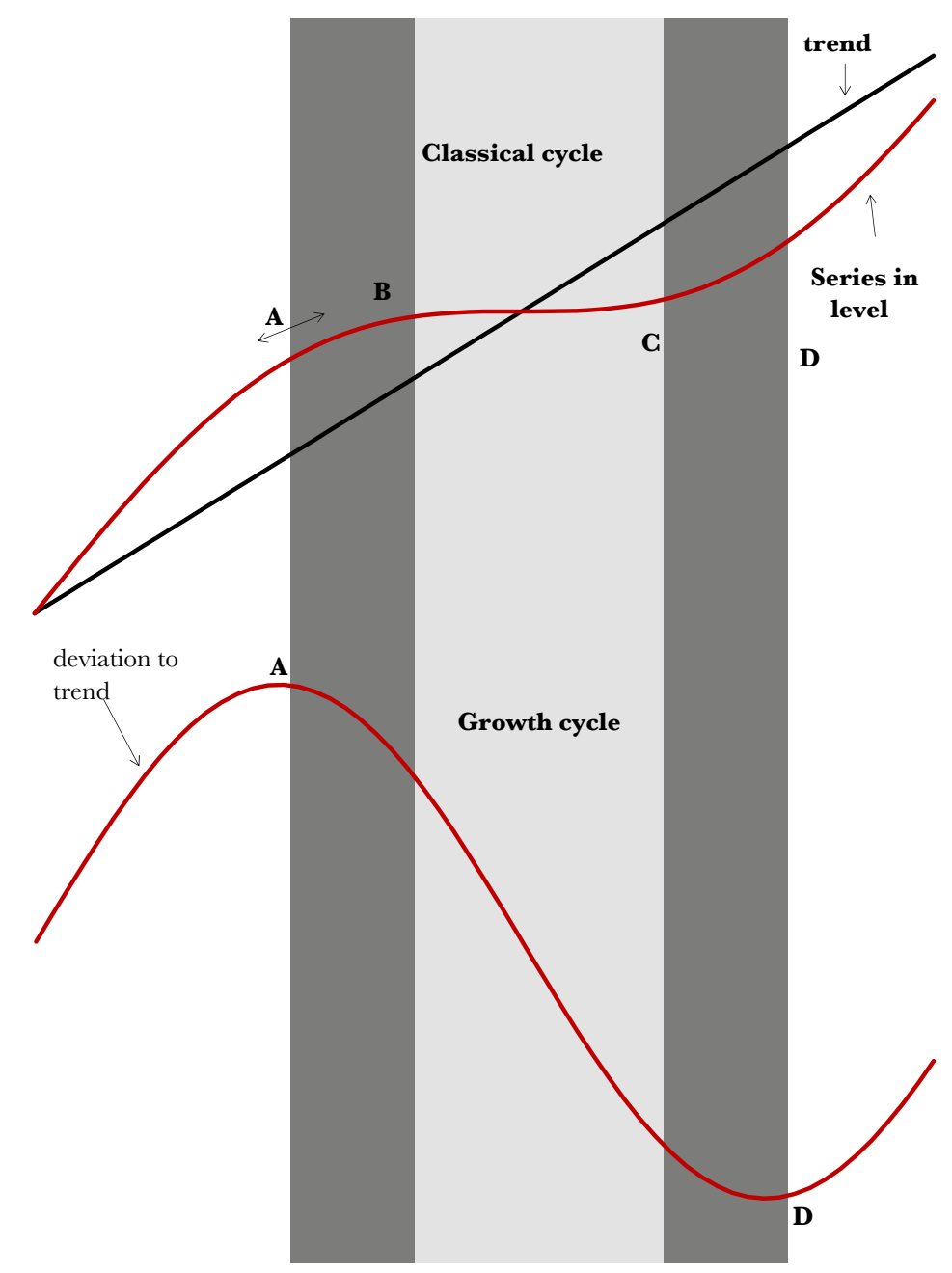

This figure compares the classical and Growth cycle phases and turning points. A and D correspond to the downturn and upturn turning points, and the shaded area corresponds to a low-growth phase. Points $\mathrm{B}$ and $\mathrm{C}$ are the peak and through of the classical definition and the light gray shaded corresponds to a recession. 
After creating the indicator, we compute the business cycle's chronology, which is the turning points that determine the phases. This is usually done with an objective methodology, being the most popular approach Bry and Boschan (1971), examples of this methodology for the Colombian economic activity are presented in Arango et al. (2007) and Alfonso et al. (2013). As mentioned, it is not enough to focus on the turning points to determine the current phase of the economy, given that small, brief, or sector-specific changes in economic activity can lead to miss-interpretations. Thus, we complement the turning points with the three D's criteria: duration, depth, and diffusion proposed by Conference Board to diagnose the current state of the economy in the traditional business cycle definition. Duration is defined as the number of periods that the current phase has prevailed; while recessions tend to be short, expansions are longer. For instance, it is usual to set that expansions last at least eighteen months long while recessions must be at least six in the Bry and Boschan algorithm. The depth refers to the magnitude of the change in the index analyzed; a small change in the indicator may not indicate a definite change in the economic activity. Finally, diffusion captures the fact that as more indicators are affected by economic conditions, they tend to move accordingly during the phase of the cycle.

Now that we presented the growth cycle interpretation and how the phases are defined, in the next section we present the estimated LMI and its chronology using the Bry and Boschan (1971) methodology, which identifies nine phases between 2001 and 2017. After that, we define whether the turning points detected are consistent with the three D's criteria and explain why it is important to consider both elements.

\section{LMI history}

The LMI is computed between March 2001 and December 2019 using the variables in Table 1. The best fit of the model considers three latent factors, each can be approximated as an AR (2) process, while the idiosyncratic processes were better approximated by a series of AR (1) processes. ${ }^{11}$ The LMI and its confidence interval at the $90 \%$ is presented in Figure 2 as the cyclical momentum of the labor market, instead of a trend restored series. ${ }^{12}$ Although the trend restoration procedure eases the comparison with any reference series, it has two main disadvantages: the cyclical patterns can be obscured or even missed if the long-term trend dominates the cyclical movements, and this procedure is an extra source of revision of the LMI as the trend is reestimated in each publication.

As discussed in the previous subsection, it is crucial for a system of business cycle indicators to determine the turning point of the indicators; thus, in table 2 we use the Bry and Boschan (1971) algorithm to determine the upturns and downturns of the LMI and its phases. During the period of analysis, we found nine turning points that define nine phases. The second column shows whether the period is a high-growth or low-growth phase; the third and fourth columns describe the starting and ending dates, while the duration in months is reported in column 5. Finally, the amplitude is shown in column 6, OECD (2004), pp. 27 defines amplitude " $\ldots$ the difference between values at peak and trough is referred to as an "amplitude" ..." In general, the larger the amplitude is, the more volatile the business cycle will be.

Before 2001 the Colombian economic activity experienced the biggest recession in its history, and the initial years of the decade show the recovery of the economic activity. Table 2 shows that between 2001 and 2019 there were nine growth cycle phases, five of which are characterized as low-growth, although we have complete information only for the last four phases. Additionally, there are four high-growth phases completely observed. While the average length or duration of the low-growth phases is twenty-one months, it is twenty-eight months for the high growth phase, this finding is consistent with the duration of the similar phases in the growth

11 The selection of this model is based on the usual AIC and BIC criteria.

12 Graphs of the cyclical components of the series are presented in appendix D. 
cycle. The highest downturn point of the indicator was reached in January 2008, while the lowest was reached in November 2009. Each phase duration is at least 15 months and cycle depth (amplitude is higher than 1,7); thus, the phases in the table satisfy these two criteria.

Figure 2. The Labor Market Indicator

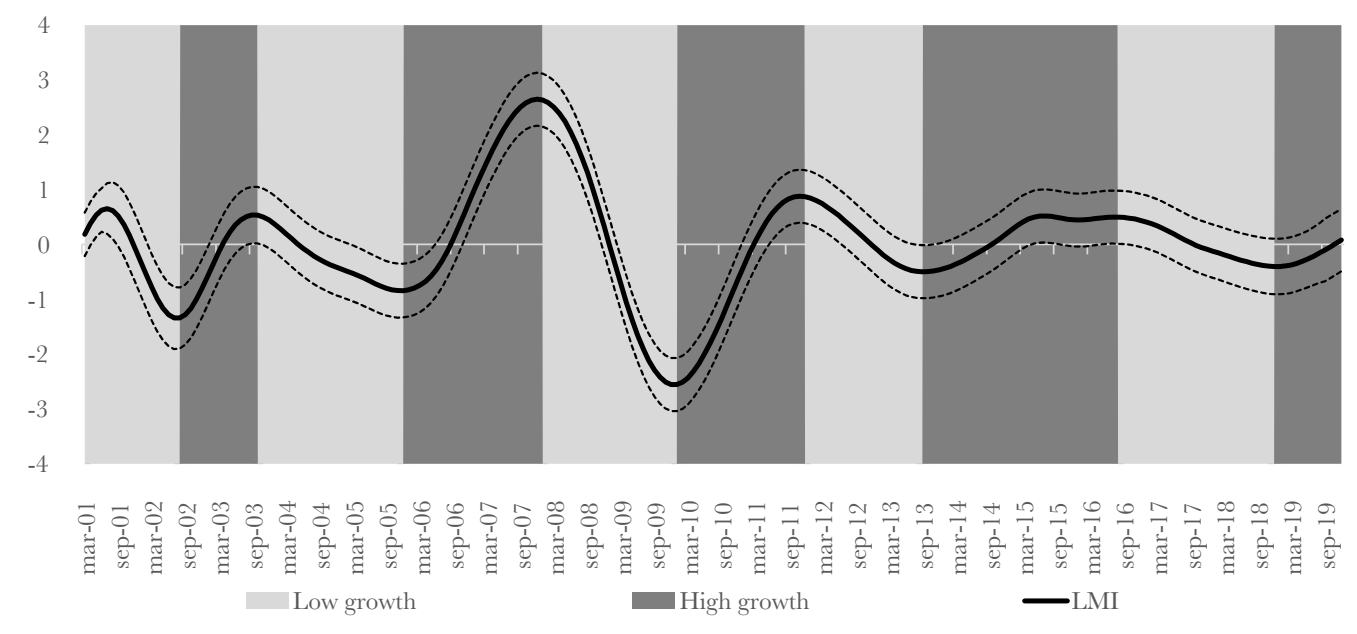

Source: author's calculations.

To describe diffusion, we focus on each series contribution into the LMI, doing so we determine whether the variables evolution coincide with the aggregate signal. However, as the estimates come from a Kalman filter the computation of the contributions is not a trivial task. We follow Koopman and Harvey (2003), who express the factors as linear combination of the observed variables. ${ }^{13}$ In the next paragraphs we present the evolution of the LMI by phases defined by the Bry and Boschan algorithm.

Table 2. Phases of the LMI

\begin{tabular}{llllrr}
\hline \multicolumn{1}{c}{ Period } & Growth-Phase & \multicolumn{1}{c}{ Start } & End & Duration & Depth \\
\hline 1 & Low & NA & July 2002 & NA & NA \\
2 & High & July 2002 & October 2003 & 15 & 1.91 \\
3 & Low & October 2003 & December 2005 & 22 & -1.40 \\
4 & High & December 2005 & January 2008 & 25 & 3.47 \\
5 & Low & January 2008 & February 2010 & 25 & -5.12 \\
6 & High & February 2010 & December 2011 & 23 & 3.37 \\
7 & Low & December 2011 & October 2013 & 22 & -1.36 \\
8 & High & October 2013 & August 2016 & 34 & 0.98 \\
9 & Low & August 2016 & January 2019 & 29 & -0.90 \\
\hline
\end{tabular}

This table presents the low and high growth phases of the LMI computed with the Bry and Boschan (1971) algorithm. We impose restrictions on the minimum duration of both phases and the whole cycle. We use the standard values of six and eighteen months.

\section{Source: author's calculations.}

13 The idea behind this procedure, is to use the Kalman filter recursions to compute weights for the observed variables. The filtered estimator of the state vector based on information available at time $t-1$ is given by $a_{t \mid t-1}=\sum_{j=1}^{t-1} w_{j}\left(a_{t \mid t-1}\right) Y_{j}$ For the case in which the transition equation corresponds to $\operatorname{VAR}(1)$, the weight vectors can be computed by the backward recursion $w_{j}\left(a_{t \mid t-1}\right) B_{t, j} K_{j} B_{t, j-1}=B_{t, j} A_{j}-w_{j}\left(a_{t \mid t-1}\right) ; \Lambda j,=t-1, t-2, \ldots, 1$, with $B_{t, t-1}=I$. The computation of the weights for smoothing follows a similar procedure to the described in the previous equations. 
The first is a low-growth phase that finishes in July 2002; however, we cannot determine the amplitude of the fall given that this is the beginning of the sample. Seven of the available series have a negative contribution with non-wage workers, the unemployment rate and vacancies leading to the index's reduction. The high-growth phase afterwards lasts fifteen months, and the downturn point of the LMI improves 1.9 with respect to the previous upturn. Even though this is a high growth phase, the LMI is negative in almost the entire period. Ten series show an improvement with objective underemployment, average wage, and industrial employment showing the greatest contribution to the change. On the other hand, the unemployment, labor force participation, and occupation rates show a reduction. Labor market conditions were not good, during these two initial phases, this behavior is consistent with general economic conditions. During 2001 and 2002, domestic demand was low and internal demand showed weak signs of recuperation. External demand was also weak as economic growth in Latin America was lower than observed in Colombia. Additionally, the recovery was sluggish during 2003, mainly due to a better world demand. This whole period coincides with a labor market recession using the traditional definition as described in Alfonso et al. (2013).

The following low-growth phase lasts twenty-two months and finishes in December 2005. The index evolution reflects the low economic growth experienced by the Colombian economy and a world demand that does not recover in 2004. Employment in the commerce and industrial sectors, as well as objective underemployment, lead the 1.4 reduction of the index; eight series have a negative behavior during this period. While the labor force participation, occupation, and unemployment rates contribute positively. The fourth phase is the longest high-growth phase, and the LMI reaches its maximum in January 2008. In this period, all the variables but labor income for non-wage workers show an improvement, being the highest contributions to this positive dynamic industrial and commercial employment and the unemployment rate. This downturn point is close to the economic activity peak found by Alfonso et al. (2013). Labor market conditions improved as a result of an outstanding economic growth during 2005 and 2007, with industry and construction as the leading sectors.

Figure 3. Decomposition of the LMI

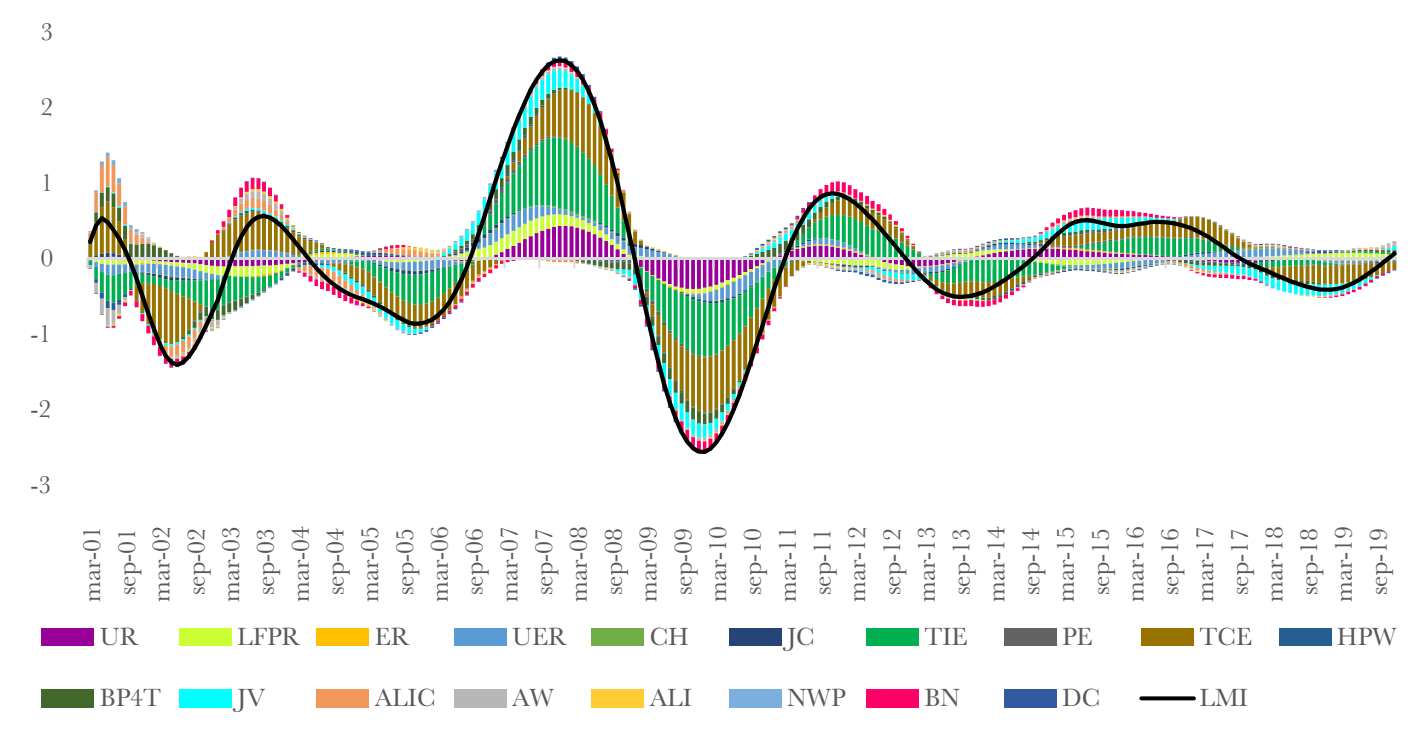

This figure presents each series contribution to the LMI following Koopman and Harvey (2003) to express the factors as linear combination of the observed variables.

Source: author's calculations

The next phase is the deepest low-growth phase that also leads to the minimum of the LMI in November 2009. This period is also categorized as a recession according to Alfonso et al. (2013), 
annual economic growth declines to $1.7 \%$ after the $3.5 \%$ observed in 2008 . During this period, industrial and commerce employment, the unemployment rate, expectations, and vacancies have the highest contributions to this decline. The upturn point lags the through found by Alfonso et al. (2013), consistent with the timing of the turning points described in Mintz (1972). The sixth phase shows a recovery of 3.37 and lasts twenty-three months. Almost all series contribute to this improvement, leading by industrial and commerce employment and the unemployment rate, while only LFPR show a small deterioration. This period is characterized by the recovery of economic activity in 2009 and 2010, which leads to a GDP and domestic demand growths in 2011 of $5.9 \%$ and $6.5 \%$. Commerce, industry and construction were the economic sectors with a better performance. However, improvements in job formality remain as a challenge.

After that, the LMI enters into a low-growth phase the following months and reach the upturn point in October 2013. Thirteen series show a reduction, being expectations, industrial and commerce employment which contribute the most to the deterioration. During this period, LFPR and discouraged workers rate had a positive contribution. These years coincide with an economic deceleration, but the unemployment rate shows a positive behavior, and the minimum wage increment was close to the inflation rate. The eighth is a high-growth phase that finishes in August 2016 after thirty-four months. The 0.98 amplitude leads the LMI to a similar downturn point as the previous one, industrial and commerce employment and bottlenecks lead to the increase of the LMI. During this period, economic conditions improved as a consequence of the oil price shock and an increment in government expenditure. The highest contribution to the index was given by the industrial and particular employment, job creation, and vacancies. The highest improvement was in 2014 as economic growth was $4.6 \%$ compared to $3.1 \%$ in 2015. After August 2016, the index starts a low growth phase that coincides with a reduction in economic activity as the GDP growth falls in 2016 and 2017 to $2.0 \%$ and $1.4 \%$. Vacancies, expectations, and industrial employment lead to the reduction. However, the growth of objective underemployment, the participation rate, and the churning rate show positive signals and alleviate the reduction of the index.

The analysis of the previous paragraphs shows that the relationship of the LMI with the traditional business cycle indicators is consistent with the description provided by Mintz (1972). First, the number of phases is higher in the growth cycle approach as we found nine phases during the same period while Alfonso et al. (2013) found four phases. Second, the downturn points of the LMI lags the two through dates of the business cycle. Another important evidence is provided by the fact that besides the unemployment rate, other variables are crucial to explain the short-term dynamics during the low and high growth phases. It is noteworthy that expectations, job creation, bottlenecks, and vacancies are highly important to describe the labor market's current state.

In table 3, we assess each series' importance in the final LMI using two criteria: the Kalman gain and the correlation with the indicator. In column 2, we present the Kalman gain that measures how new information on each variable affects the estimate of the LMI indicator, while in column four we present the correlation coefficient. The key difference among them according to Chung et al. (2014) is that while the Kalman gain reflects the influence of a series on the LMI given the whole set of variables included in the estimation, the correlation reflects not only each series direct contribution but also the contribution due to the correlation with other indicators. Despite this difference, it is important to note that variables with high gain coefficients also tend to have a higher correlation with the LMI. According to the Kalman gain, the first five series have a similar influence on the LMI. 
Table 3. Relations between Individual Variables and the LMI

\begin{tabular}{|c|c|c|c|c|}
\hline \multirow[b]{2}{*}{ Variable } & \multicolumn{2}{|c|}{ Kalman Gain } & \multirow{2}{*}{$\begin{array}{c}\text { Correlation } \\
\rho \\
\end{array}$} & \multirow{2}{*}{$\begin{array}{c}\text { with LMI } \\
\text { Rank } \\
\end{array}$} \\
\hline & $K_{t}$ & Rank & & \\
\hline $\mathrm{BP} 4$ & -0.084 & 1 & -0.794 & 2 \\
\hline JV & -0.083 & 2 & -0.806 & 1 \\
\hline TIE & -0.066 & 3 & -0.754 & 4 \\
\hline UR & 0.065 & 4 & 0.77 & 3 \\
\hline $\mathrm{BN}$ & -0.055 & 5 & -0.545 & 6 \\
\hline TCE & -0.052 & 6 & -0.658 & 5 \\
\hline ER & -0.047 & 7 & -0.273 & 11 \\
\hline ALIC & -0.046 & 8 & -0.404 & 8 \\
\hline AW & -0.042 & 9 & -0.365 & 9 \\
\hline PE & -0.028 & 10 & -0.407 & 7 \\
\hline ALI & -0.019 & 11 & -0.128 & 14 \\
\hline DC & 0.017 & 12 & 0.129 & 13 \\
\hline NWP & -0.016 & 13 & -0.021 & 17 \\
\hline $\mathrm{CH}$ & -0.007 & 14 & -0.047 & 16 \\
\hline UER & 0.005 & 15 & 0.279 & 10 \\
\hline JC & -0.004 & 16 & -0.002 & 18 \\
\hline LFPR & 0.003 & 17 & 0.2 & 12 \\
\hline HPW & 0.001 & 18 & -0.061 & 15 \\
\hline
\end{tabular}

This table presents alternative measures of the association between the LMI and the series, the second and third column presents the Kalman gain and its ranking, while the third and fourth columns present the correlation of each series with the composite indicator and its ranking.

Source: author's calculations.

\section{Robustness analysis}

The most important issue in the construction of business cycle indicators is to determine the correct chronology of the turning points, which allows to determine the low and high growth phases. Thus, it is desirable that new information has little impact on the phases previously defined. In this subsection we inspect how new information affects the LMI. Two sources may lead to a revision of the LMI. First, there is a one-month publication lag of the microdata from the household survey, then when new data is available, it will replace the estimates of those missing values based on the latent factors and the idiosyncratic structure. ${ }^{14}$ The second source of revision is the estimation of the model, as it is a statistical technique that provides the best fit conditional on the information available; thus, as new information is included, those estimates may change.

In order to check whether the introduction of new information affects the chronology of the LMI, we conduct a rolling estimation with four samples. The first sample includes information between March 2001 and December 2015, the second sample includes twelve additional

14 The variables affected by this delay in the publication are: job creation, churning, weekly hours, and the earnings measurements: average wage and average labor income. 
months, that is up to December 2016, and each subsequent sample includes twelve additional months. Table 4 compares each sample turning points with those in Table 2. Columns one to four present the different samples, while rows report the date of the original turning point. The numbers reported indicate for how manymonths each sample turning point lags the original turning point. Thus, a negative number indicates that the turning point identified with that sample leads to the turning point.

First, all estimates have the same number of turning points; that is, no additional upturns or downturns are reported with the subsamples analyzed. The first is the upturn in July 2002, which is similar in all samples since it is identified between June and August. The next turning point is a downturn in December 2003 that depending on the sample, is identified between three months later or two months earlier. The timing is similar for the rest of upturns and downturns, with the greatest difference being a lag or lead of 2 months. In conclusion, there are no big differences in the phases defined, and the LMI is robust to the introduction of new information. Thus, the introduction of new information does not affect the diagnostic made. Given that most of the series are published and not revised, and the estimates of the parameters of the statistical model do not change between estimations.

\section{The LMI and the Colombian business cycle}

In this section we provide insight of how the LMI fits when describing the effect of the business cycle on the labor market. In the first subsection we compare the LMI with the most traditional growth cycle indicators the GDP GAP and the UR GAP, which are computed as the cyclical component of the series. In the second subsection, we describe the state of the labor market combining the traditional and growth cycle definitions with a diffusion index and the LMI.

Table 4. Number of months that the turning points of the LMI change with alternative samples

\begin{tabular}{lcccc}
\hline & December 2015 & December 2016 & December 2017 & December 2018 \\
\hline July 2002 - Upturn & 1 & -1 & -1 & -1 \\
October 2003 - Downturn & 2 & -1 & -2 & -1 \\
December 2005 - Upturn & 0 & 1 & 0 & -1 \\
January 2008 - Downturn & 2 & 0 & 0 & -2 \\
February 2010 - Upturn & 2 & 1 & 0 & 1 \\
December 2011 - Downturn & 1 & -1 & -1 & -2 \\
October 2013 - Upturn & 2 & -1 & 0 & -1 \\
August 2016 - Downturn & NA & 0 & 0 & 2 \\
January 2019 - Upturn & NA & NA & NA & 1 \\
\hline
\end{tabular}

This table presents the difference between the dates of the turning points computed with different spans of information and those computed with information up to December 2018 that are presented in table 2.

Source: author's calculations.

\section{LMI and the growth cycle in Colombia}

In this subsection, we analyze the ability of the LMI as a measure of activity in the labor market and the overall economy. Thus, we compare a quarterly LMI, averaging the monthly values, with several measures of the cyclical components of the Gross Domestic Product and the Unemployment Rate. We include the following measures of the output GAP: a Hodrick 
and Prescott filter, estimates based on adaptive and rational expectations, a production function approach, the calculations from the IMF, the GAP derived from the semi-structural model (4GM), and a principal components approach. On the other hand, we include six measures of the unemployment GAP based on estimates of the NAIRU following the approaches presented by Shimer (2012); Ball and Mankiw (2002); King and Morley (2007); Perry (1970) and Julio (2001). ${ }^{15}$ Panel A of the figure 4 shows that the LMI closely follows the measures of GDP GAP, which are presented as gray lines, with synchronization of their turning points, i.e., the majority of the oscillations in economic activity are also presented in the labor market.

The LMI is usually between the minimum and the maximum values of the GDP GAP indicators, which indicates the close connection between the labor market and the economic activity. However, there are some differences in the dynamics. First, output was below its potential until 2004, and most of the measures show an increasing behavior, showing that the economy was getting out of the 1998 - 1999 recession. On the other hand, the LMI shows three phases and fluctuates below its trend. This difference might originate from the lack of information on the labor market series included in our index before 2001, and the fact that back-casting process might not be able to recover a good approximation during the crisis period. The second difference is presented between 2013 and 2014, where the GDP GAP quickly increases and the LMI does not respond at the same speed. This difference can be explained given that the economic activity improvement was mainly originated by the oil shock and may have not fully spread to labor intensive activities.

In panel B we compare the LMI and the negative of the unemployment rate GAP measures, given that a higher unemployment rate GAP signals a deterioration of the labor market. As we can see, the LMI and the measures of unemployment have a similar evolution, then, they provide a similar signal about the status of the labor market, the LMI is also in the range of the minimum and the maximum of the remaining indicators. However, some differences emerge and are worthwhile to describe; firstly, the UR GAP has a higher volatility than the LMI, this is consistent with different facts previously discussed, i) the LMI captures more dimensions of the labor market and therefore how other variables adjust to the economic conditions, ii) The LMI does not include the variation from idiosyncratic factors that may remain in the UR. Secondly, the improvement of the UR gap between 2001 and 2007 is not reflected in the LMI. As in the previous case, the difference in the trend might be caused by the issue of the beginning of the sample, but some other factors might contribute to this effect such as a higher flexibility that the Colombian labor market undergoes at the beginning of the century given a series of reforms that reduce costs associated to hiring, separations, and working hours. Although these changes are mostly structural, the cyclical component may also be affected until the economy reaches its new equilibrium. After 2007 both indicators exhibit a similar evolution, with very close turning points. Finally, in the most recent years, while the unemployment rate is higher than the average of the NAIRU measures, signaling a deterioration of the labor market, the LMI shows that its momentum is close to the trend as some other variables counter-off the reduction of the unemployment rate.

Also, there are two important differences among the evolution of the Unemployment and output gap indicators important to highlight as they signal differences in how the labor market and the overall economic activity evolved, which could imply different actions by economic authorities. First, between 2001 and 2005, the GDP gaps show less deterioration, and second between 2016 and 2018, the labor market signals a better momentum, especially if we consider the LMI that summarizes the information of expectations, industrial employment, and vacancies, which is less deteriorated than the unemployment rate. In conclusion, the LMI is a good measure of economic activity and reflect peculiarities in the labor market not included in the traditional Unemployment rate gap. Then, as discussed in Jacob and Robinson (2019), a syn-

15 The set of output GAP measures are described in Banco de la República (2020), the estimates of the NAIRU are discussed in Arango and Flórez (2016). 
thetic indicator of the labor market is useful to augment the suite of gap indicators available to the policy makers. According to the authors, a bigger set of indicators is desirable given that output gap is quarterly, not directly observable, and its estimates tend to get revised as new information is available. Thus, the use of a wider range of indicators to assess capacity pressures reduces the degree to which the output gap needs to be revised.

Figure 4. LMI and cyclical component of quarterly reference series

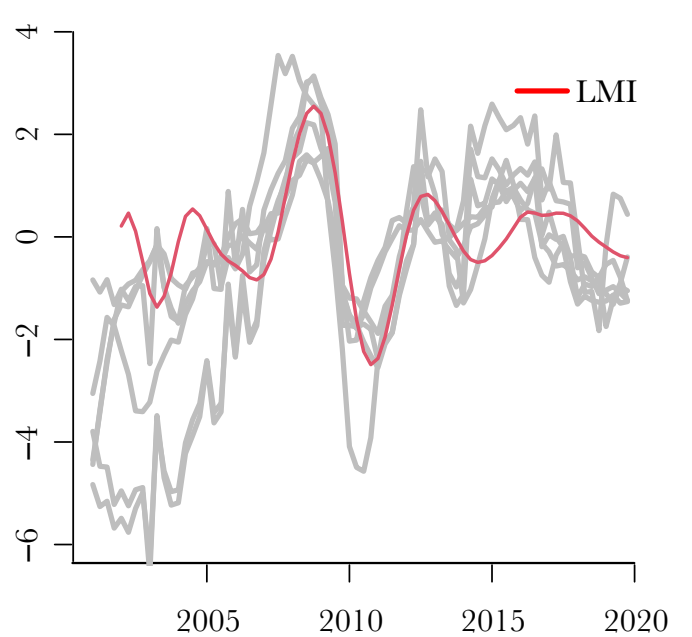

(a) Panel A

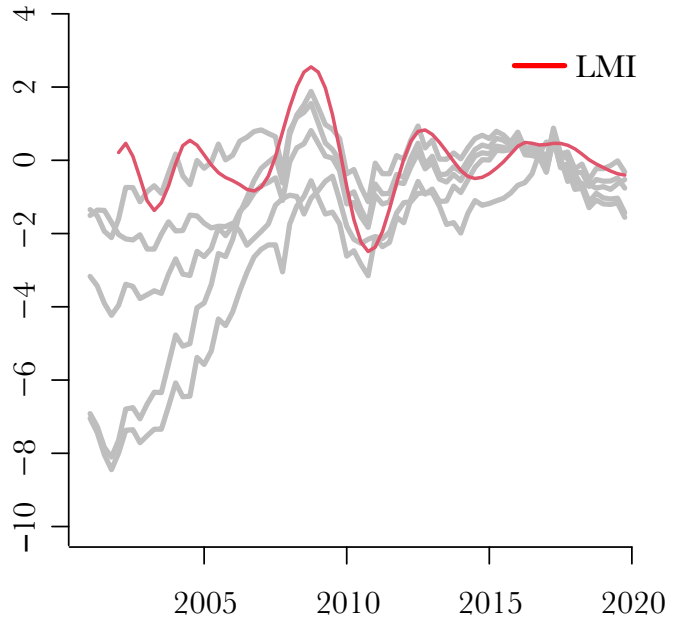

(b) Panel B

\section{The LMI and Inflationary pressures}

As discussed in the previous subsection, the LMI is a measure of the slackness in the labor market and the general economic activity, then economists are interested in knowing whether these measures of assessment of the present conditions helps to improve the assessment of inflationary pressures. Thus, in this subsection, we evaluate the in-sample and out-sample performance of the LMI and the rest of the measures of output and unemployment gaps presented in Figure 4. To this aim, we are interested in predicting headline inflation a Phillips curve augmented with expectations, estimating the following equation:

$$
\pi_{t}=\beta_{0}+\beta_{1} \pi_{t-4}^{e}+\beta_{2} \text { Indicator }_{t}
$$

Where $\pi_{t}$ denotes headline inflation, $\pi_{t-4}^{e}$ inflation expectations, Indicator $r_{t}$ each one of our alternative measures of economic activity, and $v_{t}$ is the residual term which follows a normal distribution. As a measure of inflation expectations, we use the one-year-ahead expectations of annual CPI inflation from the Quarterly Survey of Expectations of Banco de la República. ${ }^{16}$ In order to compare the in-sample performance, we estimate equation 5 for each indicator; in the column 2 of table 5, we show the $R^{2}$. As we see, the worst in-sample performance is given by the Shimer Unemployment GAP (0.954), and the best is the one of the LMI (0.967), then our indicator provides a better fit than all the other measures of slackness. To compute out of sample performance, we compute the RMSE up to four horizons, using a rolling window estimation starting in the last quarter of 2010 and finishing in the last quarter of 2018, thus we have 33 forecasts for each horizon. The best out of sample performance in the four horizons is the Unemployment GAP using Arango's methodology, followed by the measures using Bayesian and Julio approaches. The LMI is the fourth-ranked in the out-sample performance and relative to the measure of Arango, its RMSE is only 5\% higher. Moreover, our indicator performs better

16 See the methodology and the detail of the survey at https://www.banrep.gov.co/es/encuesta-trimestral-expectativas- economicas-ete. 
than all GDP measures, which means that it is advantageous in predicting headline inflation up to four horizons.

Table 5. In and Out of sample performance

\begin{tabular}{lccccc}
\multicolumn{5}{c}{ RMSE - Forecast Horizon } \\
\hline \multicolumn{1}{c}{ Output GAP measures } & $R^{2}$ & 1 & 2 & 3 & 4 \\
\hline HP filter & & & & & \\
Adaptive Expectations & 0.958 & 0.396 & 0.403 & 0.404 & 0.404 \\
Rational Expectations & 0.961 & 0.385 & 0.391 & 0.393 & 0.396 \\
Production Function & 0.961 & 0.381 & 0.387 & 0.387 & 0.389 \\
IMF & 0.961 & 0.357 & 0.364 & 0.365 & 0.367 \\
Semi-Structural model 4GM & 0.960 & 0.359 & 0.367 & 0.368 & 0.371 \\
PCA & 0.961 & 0.340 & 0.342 & 0.346 & 0.351 \\
& 0.958 & 0.372 & 0.381 & 0.383 & 0.386
\end{tabular}

Unemployment GAP measures

\begin{tabular}{llllll} 
Arango & 0.964 & 0.311 & 0.317 & 0.315 & 0.317 \\
Ball & 0.962 & 0.362 & 0.368 & 0.369 & 0.370 \\
Bayesian & 0.964 & 0.316 & 0.322 & 0.320 & 0.322 \\
Julio & 0.964 & 0.323 & 0.328 & 0.328 & 0.332 \\
King & 0.962 & 0.333 & 0.344 & 0.346 & 0.349 \\
Shimer & 0.954 & 0.394 & 0.405 & 0.407 & 0.410 \\
LMI & 0.967 & 0.329 & 0.333 & 0.333 & 0.335 \\
\hline
\end{tabular}

This table presents the RMSE of alternative GDP and Unemployment GAPS to forecast headline inflation.

Source: author's calculations.

The LMI and the diagnostic of the labor market momentum

As discussed in section 4, while the LMI diagnoses the state of the cyclical component of the Labor Market, the traditional business cycle indicators diagnose the state of the overall state of the economy, as series are considered in levels. Thus, we can combine the signals that provide these alternative indicators to get a better picture of the current state of the labor market. There are two features of the LMI that will contribute to policy analysis. First, the LMI is useful to give more information during expansions, as it characterizes them as low or high growth phases, second, as the downturns tend to lead peaks, they might be an early signal of the beginning of a recession, which has been used by Anas and Ferrara (2004) to construct the ABCD approach to predict signs of deterioration that might lead to a recession. Understanding then these connections is very useful for economic policy design and analysis.

Thus, to provide a more complete analysis of the labor market we introduce a diffusion index and we compare the phases of the LMI with those obtained in the diffusion index (e.g., Alfonso et al. (2013)). The diffusion index is computed as the percentage of series for which the annual change improves minus the percentage of series for which conditions worsen, then if the index is above zero the majority of the series are improving but if the index is negative, it may indicate a recession. Then, when the index crosses zero it marks a turning point, to 
determine the business cycle phase we also consider the duration of the phases in the same fashion than in the Bry and Boschan (1971) algorithm.

Figure 5. Diffusion Index of the labor market

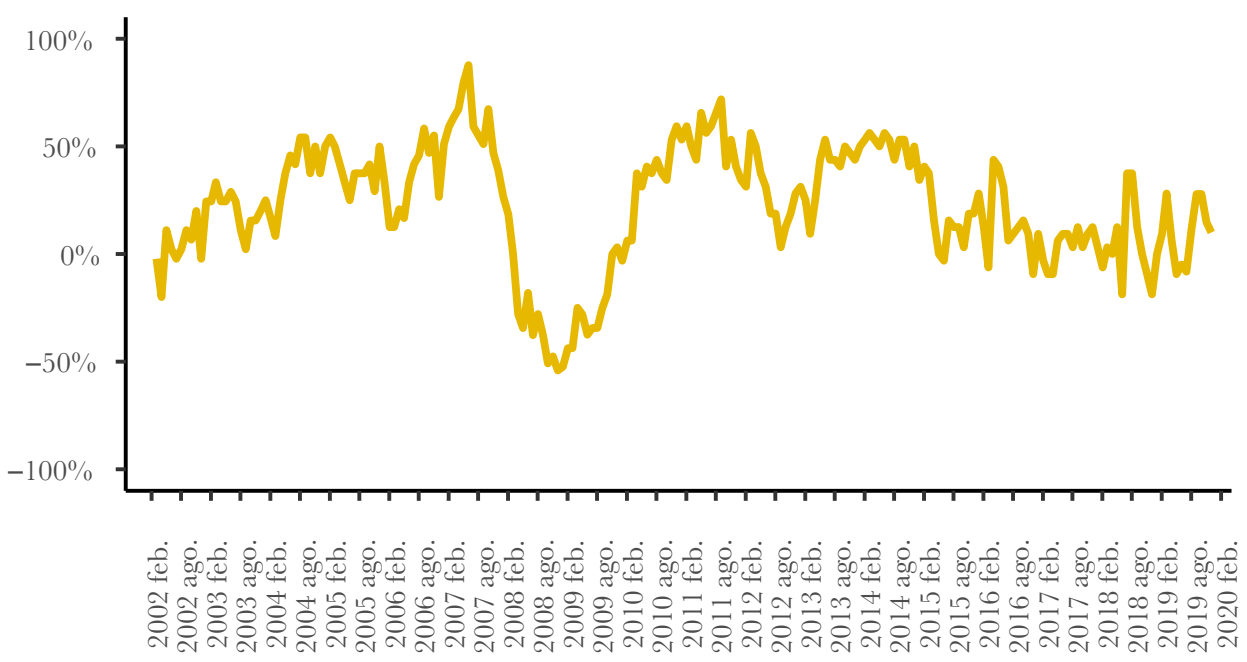

Source: author's calculations

Figure 5 shows that between 2001 and 2019 we identify one recession that starts in June 2008 and finishes in January 2009, then the period before and after that recession is considered as an expansion. The relationship between both indices is consistent with the predictions of economic theory as: $i$ ) there are more phases in the LMI than in the diffusion indicator, ii) the peak of the diffusion index occurs in June 2008, that lags by five months the downturn point (January 2008), and iii) the trough in the diffusion index, July 2009, leads by four months the upturn point (October). Moreover, the LMI shows its maximum and minimum at the turning points associated with the peak and through of the diffusion index, which may indicate that in those periods the permanent and transitory components of the labor market experience a similar behavior.

\section{Conclusions}

In developing countries, the unemployment rate might not the best indicator to track the current state of the labor market due to the existence of rigidities that impede labor to freely flow among occupations. For instance, this indicator does not capture that workers who lose their job engage in informal activities. In this document, we present the Labor Market Index as a tool to analyze the current state of the labor market, focusing on the cyclical similarities of a broad set of labor market series, removing the trend that might obscure the similarities in the cyclical behavior. Its construction is based on a two-step methodology similar to Chung et al. (2014), extracting the maximum common variation in the first stage and computing the first principal component of the projected series in the second stage. This indicator is based on the assumption that the momentum of the labor market is described by latent factors that drive the evolution of all variables. The proposed methodology accounts for missing observations, optimally determines the influence of each series, and removes idiosyncratic behavior that will contaminate the evolution of the index. Our estimations show ten phases between 2001 and 2019, in which industrial and commercial employment, expectations, the presence of bottlenecks, and the unemployment rate plays an important role in the evolution of the indicator.

Moreover, the evolution of the LMI is similar to that of the most traditional growth cycle indicators, the GDP and the unemployment rate gaps, which confirms that our indicator is a 
good measure of activity in the Labor Market and the overall economy. However, there are some differences which explain which movements in the labor market are not captured by the unemployment rate and which movements in the labor market are not presented in the overall economy. For instance, during the 2016-2018 period the negative GDP GAP has not been presented in the LMI, this difference is explained by the positive contribution of vacancies, industrial and commerce employment. Additionally, we show that our indicator can be used to forecast headline inflation, and in fact is the best in sample predictive power and it is high ranked in the out sample predictive power. Moreover, the LMI helps to get a better characterization of the business cycle, combining it with a diffusion index; we see that before the 2008 expansion, there were four growth cycle phases, the majority with a modest growth, with the higher variation in the high-growth phase that coincides with the end of the expansion. Afterward, the recession also coincides with the low-growth phase that leads to the minimum of the LMI. The next expansion in our diffusion indicator has had five growth cycle phases, none with similar amplitude to the ones that mark the end of the expansion and lead to the crisis. Moreover, the timing between the turning points behaves as predicted by Mintz (1972) as downturn leads the peak and upturns lag the through. Finally, future research using this indicator may analyze its predictive power to determine turning points, using an approach similar to Anas and Ferrara (2004) combining information of the traditional business cycle and the growth cycle. Another possible extension is to combine the diagnosis of the momentum of the Labor market from the LMI with alternative economic activity measures constructed for different economic sectors and methodologies to improve the assessment of the momentum of the overall economy.

\section{Abbreviation}

4GM: 4-Good Model used for forecast in the Colombian central bank; AIC: Akaike Information Criterion; ALI: Average Labor Income; ALIC: Average Labor Income - Commerce; AR: Auto-Regressive; ARIMA: Auto-Regressive Integrated Moving Average; AW: Average Wage; BIC: Bayesian Information Criterion; BN: Bottlenecks; BP4: employment expectations; BR: Banco de la República; BK: Baxter and King; CPI: Consumer Price Index; DANE: Departamento Administrativo Nacional de Estadística; DC: Discouraged workers; DFM: Dynamic Factor Models; EEE: Encuesta de Expectativas Económicas; EMCM: Encuesta Mensual de Comercio al por Menor; EMM: Encuesta Mensual Manufacturera; GDP: Gross Domestic Product; GEIH: Gran Encuesta Integrada de Hogares; HP: Hodrick and Prescott; HPW: average Weekly Hours; i.i.d.: Independent and identically distributed; IMF: International Monetary Fund; JC:Job Creation; JV: Job Vacancies; LFPR: Labor Force Participation Rate; LMI: Labour Market Index; LOWESS: Locally Weighted Scatter Plot Smoothing; NAIRU: Non-Accelerating Inflation Rate of Unemployment; NWP: Non-Wage workers Proportion; OECD: Organisation for Economic Co-operation and Development; PAT: Phase Average Trend; PCA: Principal Component Analysis; PE: Employees in Particular firms; PILA: Planilla Integrada de Liquidación de Aportes; RMSE: Root of the Mean Squared Errors; TEC: Total Employment in Commerce; TIE: Total Industry Employment; TRAMO-SEATS: Time-series Regression with ARIMA noise, Missing values and Outliers - Signal Extraction in ARIMA Time-Series; UER: objective underemployment rate by hours; UR: Unemployment Rate; VAR: Vector Auto-Regression.

\section{Acknowledgements}

The authors gratefully acknowledge the valuable comments of Luis Melo, Enrique Lopez, Karen Pulido, and the participants at the VIII internal research workshop of Banco de la República and LACEA- LAMES 2019 annual meeting to previous versions of the document. Any remaining errors are exclusive responsibility of the authors. 


\section{Authors' contributions}

All authors read and approved the final manuscript.

\section{Funding}

None.

\section{Availability of data and materials}

The information from the different economic sector surveys can be obtained directly from the DANE web page, and the micro data of the household survey is also available on their web page. On the other hand, information and code produced by Banco de la República are protected by intellectual and property rights, then they must be directly asked to the Colombian Central Bank using the attention to citizens email: atencionalciudadano@banrep.gov.co, all details and instructions can be found in: https://www.banrep.gov.co/en/attention-to-citizens.

\section{Competing Interests}

The authors declare that they have no competing interests.

\section{Author details}

†e-mail: dcristbo@banrep.gov.co, Banco de la República, Bogotá, Colombia.

†e-mail: mdh5718@psu.edu, Pennsylvania State University, EEUU.

§e-mail: mramosve@banrep.gov.co, Banco de la República, Bogotá, Colombia. 


\section{Appendix A: Variables included in previous studies}

Table 6. Variables included in previous studies

\begin{tabular}{|c|c|c|c|}
\hline Hakkio and Willis & Barnes et al & $\begin{array}{c}\text { Zimitrowicz and } \\
\text { Khan }\end{array}$ & Chung et al \\
\hline
\end{tabular}

Unemployment and Underemployment $\begin{array}{ll}\text { Unemployment rate (U3) } & \text { Unemployment Rate > } \\ \text { Broad unemployment rate (U6) } & 16 \text { yr. Unemployed - < }\end{array}$

Unemployed 27 or more weeks 5 Weeks

Part time for economic reasons

Participation rate

Employment

Employment-population ratio All Employees: Total Manufacturing employment index (ISM) Private nonfarm payroll employment Temporary help employment

Workweeks

Aggregate weekly hours

Wages

Average hourly earnings

Vacancies
Help-Wanted index (Newspapers)
Unemployment rate

Part time for economic reasons

Part Time for economic reasons

Participation Rate: > 16 yr. +

Participation rate Participation rate 25-54

Participation rate

Private payroll employment Government payroll employment Temporary help employment

Average weekly hours

Aggregate Hours Nonfarm Average Weekly Hours - Private A (n)

Average weekly hours (production)

Annual wage growth

Average weekly hours

Average hourly earnings (production)

help-wanted index (composite)

Hiring rate

Transition rate from unemployment to employment

Layoffs and Quits

Initial claims Job losers Quits Initial Claims rate Job leavers
Insured unemployment rate

Job losers unemployed less than 5 weeks Quit rate

Job leavers unemployed less than 5 weeks 
Table 6. (continued). Variables included in previous studies

\begin{tabular}{|c|c|c|c|}
\hline Hakkio and Willis & Barnes et al & $\begin{array}{l}\text { Zimitrowicz and } \\
\text { Khan }\end{array}$ & Chung et al \\
\hline \multicolumn{4}{|l|}{ Consumer and business surveys } \\
\hline $\begin{array}{l}\text { Job availability index (Confe- } \\
\text { rence Board) }\end{array}$ & $\begin{array}{l}\text { Jobs Hard to Get (Con- } \\
\text { ference Board) }\end{array}$ & & $\begin{array}{l}\text { Jobs plentiful v. hard to get } \\
\text { Hiring plans }\end{array}$ \\
\hline \multicolumn{4}{|l|}{ Percentage of firms planning } \\
\hline $\begin{array}{l}\text { to increase employment (NFIB) } \\
\text { Percentage of firms with posi- } \\
\text { tions not able to fill right now } \\
\text { (NFIB) Unemployment fore- } \\
\text { cast (Blue Chip) }\end{array}$ & & & Jobs hard to fill \\
\hline \multicolumn{4}{|l|}{$\begin{array}{l}\text { Expected job availability (U of } \\
\text { Michigan) Expected job availa- } \\
\text { bility (Conference Board) }\end{array}$} \\
\hline Other variables & & Job finding Rate Se- & \\
\hline $\begin{array}{l}\text { Announced job cuts (Challen- } \\
\text { ger-Gray-Christmas) }\end{array}$ & $\begin{array}{l}\text { Job-finding rate, } \underline{\mathrm{R}} . \\
\text { Shimer }(2005)\end{array}$ & & \\
\hline
\end{tabular}

\section{Appendix B: State space representation of the DFM}

The dynamic factor explained in the text for $n_{v}$ variables is:

$$
\begin{aligned}
& X_{t\left(n_{v}, 1\right)}=\Lambda_{\left(n_{v}, n_{f}\right)} F_{t\left(n_{f}, 1\right)}+u_{t\left(n_{v}, 1\right)} \\
& F_{t\left(n_{f}, 1\right)}=\sum_{i=1}^{p_{f}} A_{i\left(n_{f}, n_{f}\right)} F_{t-i}+\eta_{f_{t}} \\
& U_{t}=\sum_{j=1}^{p_{u}} C_{j\left(n_{v}, n_{v}\right)} U_{t-j}+\eta_{u_{t}}
\end{aligned}
$$

Using a standard state space representation, we redefine the above model in the following two equations:

$$
\begin{aligned}
& Y_{t}=Z \alpha_{t} \\
& \alpha_{t}=T \alpha_{t-1}+H \epsilon_{t}
\end{aligned}
$$

Equation (A.4) is known as the measurement equation that linearly relates the observed variables $Y_{t}=X_{t}$ and the states $\alpha_{t}=\left\{F_{t}, F_{t-1}, \ldots, F_{t-p_{f}+1}, U_{t}, U_{t-1}, \ldots, U_{t-p_{u}+1}\right\}^{\prime}$ and

$$
Z=\left\{\begin{array}{llll}
\Lambda_{\left(n_{v}, n_{f}\right)} & \left.0_{\left(n_{v}, n_{f} \times\left(p_{f}-1\right)\right.}\right) & I_{\left(n_{v}, n_{v}\right)} & 0_{\left(n_{v}, n_{v} \times\left(p_{u}-1\right)\right)}
\end{array}\right\}
$$




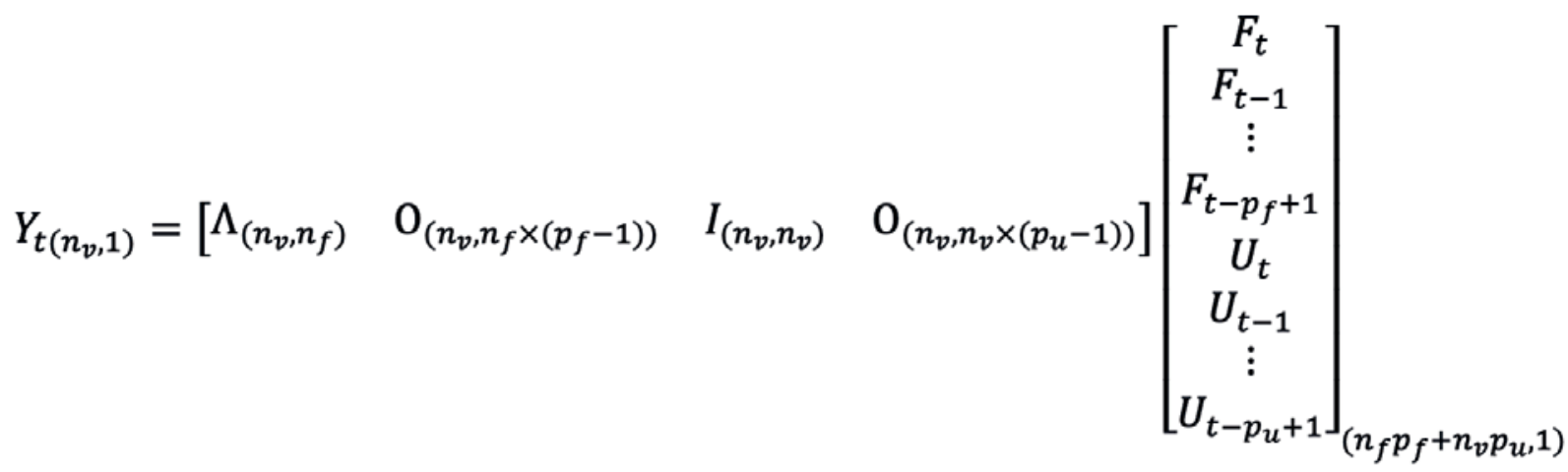

Equation (B.5) is known as the transition equation and describes the dynamic of the state vector $\alpha_{t}$, In this particular case this will be:

$$
\left[\begin{array}{c}
F_{t} \\
F_{t-1} \\
\vdots \\
F_{t-p_{t}+1} \\
U_{t} \\
U_{t-1} \\
\vdots \\
U_{t-p_{u}+1}
\end{array}\right]
$$

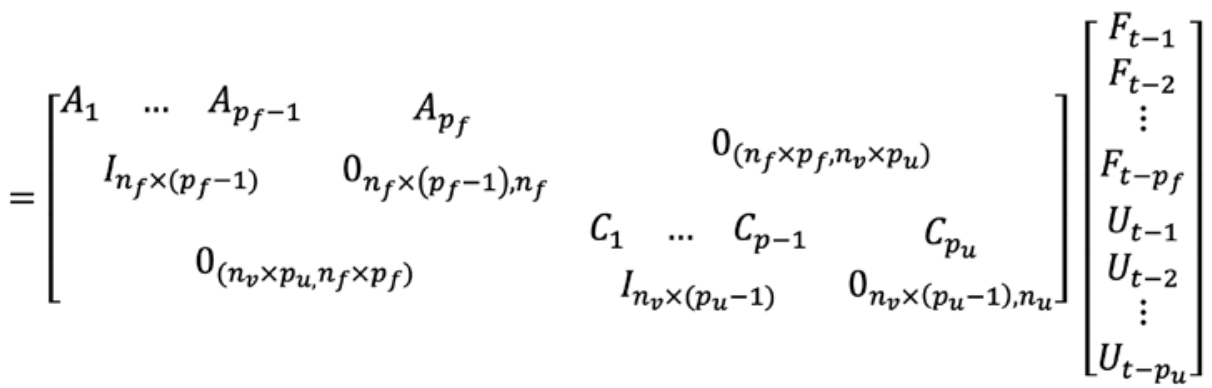$$
+\left[\begin{array}{cccc}
I_{n_{f}} & 0_{n_{f}, n_{f} \times\left(p_{f}-1\right)} & 0_{n_{f}, n_{v}} & 0_{n_{f}, n_{v} \times\left(p_{u}-1\right)} \\
0_{n_{f} \times\left(p_{f}-1\right), n_{f}} & 0_{n_{f} \times\left(p_{f}-1\right), n_{f} \times\left(p_{f}-1\right)} & 0_{n_{f} \times\left(p_{f}-1\right), n_{v}} & 0_{n_{f} \times\left(p_{f}-1\right), n_{v} \times\left(p_{u}-1\right)} \\
0_{n_{v}, n_{f}} & 0_{n_{v}, n_{f} \times\left(p_{f}-1\right)} & I_{n_{v}} & 0_{n_{v}} \\
0_{n_{v} \times\left(p_{u}-1\right), n_{f}} & 0_{n_{v} \times\left(p_{u}-1\right), n_{f} \times\left(p_{f}-1\right)} & 0_{n_{v} \times\left(p_{u}-1\right), n_{v}} & 0_{n_{v} \times\left(p_{u}-1\right), n_{v} \times\left(p_{u}-1\right)}
\end{array}\right]\left[\begin{array}{c}
\eta_{f} \\
0_{n_{f} \times\left(p_{f}-1\right)} \\
\eta_{u} \\
0_{n_{v} \times\left(p_{u}-1\right)}
\end{array}\right]
$$

Thus, we define

$$
\begin{aligned}
& T=\left[\begin{array}{cccccccc}
A_{1} & \ldots & A_{p_{f}-1} & & A_{p_{f}} & & & 0_{\left(n_{f} \times p_{f}, n_{v} \times p_{u}\right)} \\
I_{n_{f} \times\left(p_{f}-1\right)} & 0_{n_{f} \times\left(p_{f}-1\right), n_{f}} & & & \\
& & & C_{1} & \ldots & C_{p-1} & C_{p_{u}} \\
& & & 0_{\left(n_{v} \times p_{u}, n_{f} \times p_{f}\right)} & & I_{n_{v} \times\left(p_{u}-1\right)} & 0_{n_{v} \times\left(p_{u}-1\right), n_{u}}
\end{array}\right], \\
& H=\left[\begin{array}{cccc}
I_{n_{f}} & 0_{n_{f}, n_{f} \times\left(p_{f}-1\right)} & 0_{n_{f}, n_{v}} & 0_{n_{f}, n_{v} \times\left(p_{u}-1\right)} \\
0_{n_{f} \times\left(p_{f}-1\right), n_{f}} & 0_{n_{f} \times\left(p_{f}-1\right), n_{f} \times\left(p_{f}-1\right)} & 0_{n_{f} \times\left(p_{f}-1\right), n_{v}} & 0_{n_{f} \times\left(p_{f}-1\right), n_{v} \times\left(p_{u}-1\right)} \\
0_{n_{v}, n_{f}} & 0_{n_{v}, n_{f} \times\left(p_{f}-1\right)} & I_{n_{v}} & 0_{n_{v}} \\
0_{n_{v} \times\left(p_{u}-1\right), n_{f}} & 0_{n_{v} \times\left(p_{u}-1\right), n_{f} \times\left(p_{f}-1\right)} & 0_{n_{v} \times\left(p_{u}-1\right), n_{v}} & 0_{n_{v} \times\left(p_{u}-1\right), n_{v} \times\left(p_{u}-1\right)}
\end{array}\right],
\end{aligned}
$$


and

$$
\epsilon_{t}=\left[\begin{array}{c}
\eta_{f} \\
0_{n_{f} \times\left(p_{f}-1\right)} \\
\eta_{u} \\
0_{n_{v} \times\left(p_{u}-1\right)}
\end{array}\right]
$$

Where matrices $Z, T$ and $\mathrm{H}$ are design matrices.

\section{Appendix G. Unit root test.}

Table 7: Unit root test - Dickey-Fuller.

\begin{tabular}{lcl}
\hline \multicolumn{1}{c}{ Variables } & Unit root & Type \\
\hline BP4T & YES & none \\
GB & YES & none \\
CHRT & YES & none \\
DESM1T & YES & none \\
HPW & YES & drift \\
IMED NW & YES & non \\
ISR & YES & drift \\
ITE & YES & drift \\
JCT & YES & none \\
NT MMM & YES & none \\
NWPET & YES & drift \\
Particular & YES & trend \\
TD & YES & none \\
TGP & YES & drift \\
TO & YES & none \\
TSOH & YES & trend \\
Vac73m & YES & none \\
Wmedio 13A & YES & drift \\
\hline
\end{tabular}

This table shows the unit root test by using Dickey-Fuller. The third column presents the type of the specification, considering none, drift or trend. If type is set to "none" neither an intercept nor a trend is included in the test regression. If it is set to "drift" an intercept is added and if it is set to "trend" both an intercept and a trend is added. 


\section{Appendix D: Cyclical components included in the LMI}

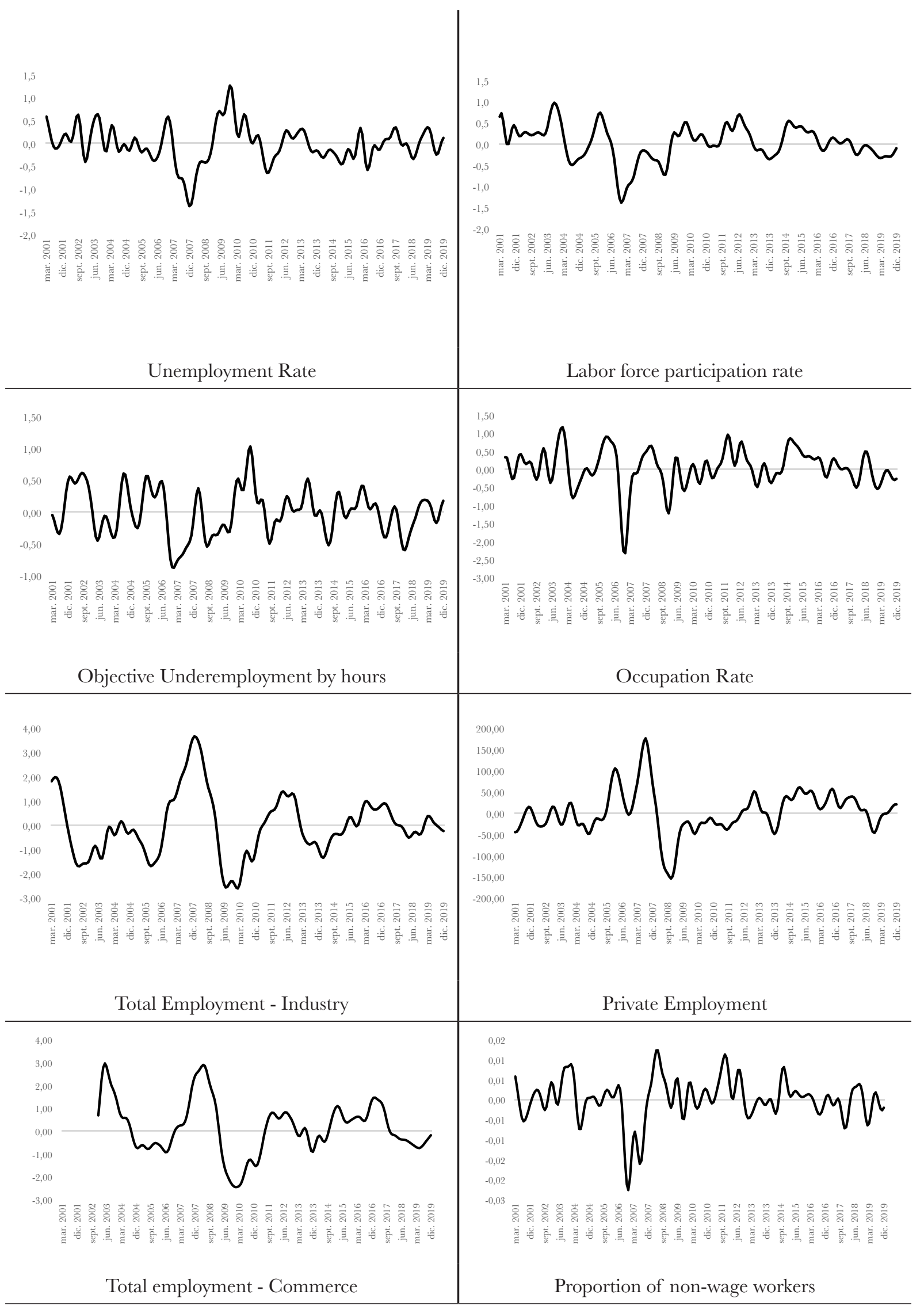




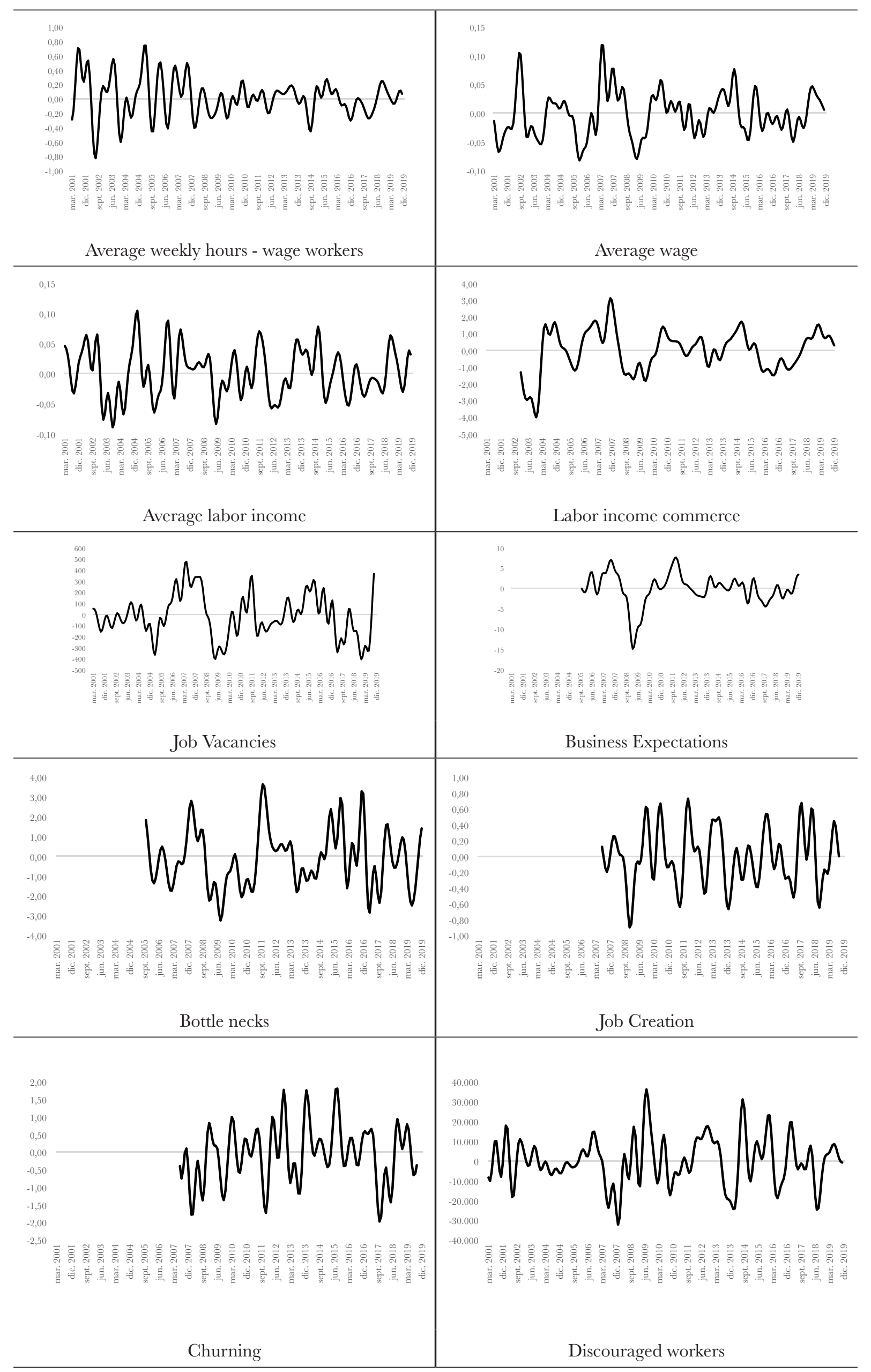




\section{References}

Alfonso V, Arango L, Arias F, Cangrejo G, Pulido J (2013). Ciclos de negocios en Colombia, 1975-2011. Lecturas de Economía, (78): 115-149.

Anas J, Ferrara L (2004). Detecting Cyclical Turning Points: The ABCD Approach and Two Probabilistic Indicators. Fournal of Business Cycle Measurement and Analysis, 2004(2): 193-225. https://doi.org/10.1787/jbcma-v2004-art12-en

Arango L (2013). Puestos de trabajo vacantes según anuncios de la prensa escrita de las siete principales ciudades de Colombia. Borradores de Economía 793, Banco de la República de Colombia. https://doi.org/10.32468/be.793

Arango L, Arias F, Flórez, L, Jalil M (2007). Cronología de los ciclos de negocios recientes en Colombia. Borradores de Economía 461, Banco de la República de Colombia. https:// doi.org/10.32468/be.461

Arango L, Flórez L (2016). Determinants of structural unemployment in Colombia. A search approach. Borradores de Economía 969, Banco de la República de Colombia. https://doi. org/10.32468/be.969

Arango L, Parra F, Pinzón A (2015). El ciclo económico y el mercado de trabajo en Colombia: 1984-2014. Borradores de Economía 911, Banco de la República de Colombia. https:// doi.org/10.32468/be.911

Ball L, Mankiw N (2002). The NAIRU in Theory and Practice. Fournal of economic Perspectives, 16(4):115-136. https://doi.org/10.1257/089533002320951000

Banbura M, Modugno M (2012). Maximum likelihood estimation of factor models on datasets with arbitrary pattern of missing data. Fournal of Applied Econometrics, 29 (1):133-160. https://doi.org/10.1002/jae.2306

Banco de la República (2020). Informe de Política Monetaria - abril de 2020. Technical report. Banco de la República, Bogotá, Colombia. https://repositorio.banrep.gov.co/bitstream/handle/20.500.12134/9842/informe de politica monetaria abril 2020.pdf?sequence $=1$ \&isAllowed $=\mathrm{y}$. Accessed 18 Dec 2020.

Barnes M, Chahrour R., Olivei, G, Tang G (2007). A principal components approach to estimating labor market pressure and its implications for inflation. Research Department Public Policy Briefs 07-2. Federal Reserve Bank of Boston, Boston, EE.UU.

Boivin J, Ng S (2006). Are more data always better for factor analysis? Fournal of Econometrics, 132(1): 169-194. https://doi.org/10.1016/j.jeconom.2005.01.027

Bry G, Boschan G (1971). Cyclical Analysis of Time Series: Selected Procedures and Computer Programs. NBER Books. National Bureau of Economic Research, Inc.

Cho J, Cooley T (1994). Employment and hours over the business cycle. Fournal of Economic Dynamics and Control, 18(2): 411-432. https://doi.org/10.1016/0165-1889(94)90016-7

Chung H, Fallick B, Nekarda C, Ratner D (2014). Assessing the Change in Labor Market Conditions. Finance and Economics Discussion Series 2014-109, Divisions of Research \& Statistics and Monetary Affairs. Federal Reserve Board, Washington, D.C.

Cristiano D, Hernández M, Pulido J (2012). Pronósticos de corto plazo en tiempo real para la actividad económica colombiana. Borradores de Economía 724, Banco de la República de Colombia. https://doi.org/10.32468/be.724

Davis S (1987). Fluctuations in the pace of labor reallocation. Carnegie-Rochester Conference Series on Public Policy, 27:335 - 402. https://doi.org/10.1016/0167-2231(87)90013-3 
Flórez L, Morales L, Medina D, Lobo, J. (2017). Labour flows across firm's size, economic sectors and wages: evidence from employer-employee linked panel. Borradores de Economía 1013, Banco de la República de Colombia. https://doi.org/10.32468/be.1013.

Forni M, Hallin M, Lippi M, Reichlin L (2005). The generalized dynamic factor model. fournalof the American Statistical Association, 100(471):830-840. http://dx.doi.org/10.2307/27590616

Gómez V, Maravall A (1996). Programs TRAMO and SEATS, Instruction for User (Beta Version: September 1996). Working Papers 9628. Servicio de Estudios - Banco de España. https://www.bde.es/f/webbde/SES/Secciones/Publicaciones/PublicacionesSeriadas/ DocumentosTrabajo/96/Fich/dt9628e.pdf Accessed 30 Aug 2019.

Hakkio G, Willis J (2013). Assessing labor market conditions: the level of activity and the speed of improvement. Macro Bulletin, Federal Reserve Bank of Kansas City, issue July 18: 1-2. http://dx.doi.org/10.17016/FEDS.2014.109

Harvey A (1990). Forecasting, Structural Time Series Models and the Kalman Filter. Cambridge University Press. https://doi.org/10.1017/CBO9781107049994.

Jacob P, Robinson F (2019). Suite as! Augmenting the Reserve Bank's output gap indicator suite. Reserve bank of New Zealand analytical notes series AN2019/08, Reserve Bank of New Zealand.

Julio J (2001). How Uncertain are NAIRU Estimates in Colombia? Borradores de Economía 184, Banco de la República de Colombia. https://doi.org/10.32468/be.184

Kaiser R, Maravall A (1999). Estimation of the business cycle: A modified Hodrick-Prescott filter. Spanish Economic Reviewe, 1(2): 175-206. https://doi.org/10.1007/s101080050008

Kamil H, PulidoJ, Torres J (2010). El IMACO: un índice mensual líder de la actividad económica en Colombia. Borradores de Economía 609, Banco de la República de Colombia. https://doi.org/10.32468/be.609

King T, Morley J (2007). In search of the natural rate of unemployment. Fournal of Monetary Economics, 54(2):550-564. https://doi.org/10.1016/j.jmoneco.2005.11.002

Koopman S, Harvey A (2003). Computing observation weights for signal extraction and filtering. Fournal of Economic Dynamics and Control, 27(7):1317-1333. https://doi.org/10.1016/ $\underline{\mathrm{S} 0165-1889(02) 00061-1}$

Kydland F, Prescott E (1991). Hours and employment variation in business cycle theory. Economic Theory, 1(1):63-81. https://doi.org/10.1007/BF01210574

Lilien D (1982). Sectoral shifts and cyclical unemployment. Fournal of Political Economy, 90(4):777793. http://dx.doi.org/10.1086/261088

Loungani P (1986). Oil Price Shocks and the Dispersion Hypothesis. The Review of Economics and Statistics, 68(3):536-539. https://doi.org/10.2307/1926035

Maximo C, Yuliya L, Perez Q (2015). Can we use seasonally adjusted variables in dynamic factor models? Studies in Nonlinear Dynamics E Econometrics, 19(3):377-391. https://doi. org/10.1515/snde-2013-0096

Mintz I (1972). Dating American Growth Cycles. In Economic Research: Retrospect and Prospect, Volume 1, The Business Cycle Today, NBER Chapters, pages 39-88. National Bureau of Economic Research, Inc.

Mitchell W (1927). Business Cycles: The Problem and Its Setting. NBER Books. National Bureau of Economic Research, Inc. 
Mondragón-Vélez C, Na X, Wills D, Kugler A (2010). Labor market rigidities and informality in Colombia [with comment]. Economía, 11(1):65-101.

Morales L, Hermida D, Davalos E (2018). The interaction between formal and informal labor dynamics: Revealing job flows from household surveys. Borradores de Economía 1090, Banco de la República de Colombia. https://doi.org/10.32468/be.1090

Morales L, Medina D (2016). Labor Fluidity and Performance of Labor Outcomes in Colombia: Evidence from Employer-Employee Linked Panel. Borradores de Economía 926, Banco de la República de Colombia. https://doi.org/10.32468/be.926

Nieto F, Melo L (2001). About a Coincident Index for the State of the Economy. Borradores de Economía 194, Banco de la República de Colombia. https://doi.org/10.32468/be.194

Perry G (1970). Changing labour markets and inflation. Brookings Papers on Economic Activity, Economic Studies Program, The Brookings Institution, vol. 1(3):411-448. https://doi. org/10.2307/2534139

Ruiz E, Poncela P (2012). More is not always better: back to the Kalman filter in dynamic factor models. DES - Working Papers, Statistics and Econometrics, WS 122317, Universidad Carlos III de Madrid, Departamento de Estadística.

Shimer R (2005). The Cyclical Behavior of Equilibrium Unemployment and Vacancies. American Economic Revierw, 95(1):25-49. https://doi.org/10.1257/0002828053828572

Shimer R (2012). Reassessing the Ins and Outs of Unemployment. Review of Economic Dynamics, 15(2):127-148. https://doi.org/10.1016/j.red.2012.02.001

Stock J, Watson M (1988). A probability model of the coincident economic indicators. NBER Working Papers 2772, National Bureau of Economic Research, Inc. https://ssrn.com/ abstract $=226857$

Stock J, Watson M (2011). Dynamic factor models. In Oxford Handbook on Economic Forecasting, eds. Michael P. Clements and David F. Hendry. Oxford: Oxford University Press. https://doi. org/10.1093/oxfordhb/9780195398649.013.0003

Stock J, Watson M (1989). New Indexes of Coincident and Leading Economic Indicator. In NBER Macroeconomics Annual 1989, Volume 4, NBER Chapters, pages 351-409. National Bureau of Economic Research, Inc. https://doi.org/10.1086/654119

Stock J, Watson M (1993). A Procedure for Predicting Recessions with Leading Indicators: Econometric Issues and Recent Experience. In Business Cycles, Indicators and Forecasting, NBER Chapters, pages 95-156. National Bureau of Economic Research, Inc. http://www.nber. org/chapters/c7190 Accessed 25 Aug 20.

Zmitrowicz K, Khan M (2014). Beyond the Unemployment Rate: Assessing Canadian and U.S. Labour Markets Since the Great Recession. Bank of Canada Review, 2014 (Spring): 42-53. 